Activation of the inflammatory transcription factor nuclear factor interleukin- 6 during inflammatory and psychological stress in the brain

Fuchs et al. 


\title{
Activation of the inflammatory transcription factor nuclear factor interleukin-6 during inflammatory and psychological stress in the brain
}

Franziska Fuchs, Jelena Damm, Rüdiger Gerstberger, Joachim Roth and Christoph Rummel ${ }^{*}$

\begin{abstract}
Background: The transcription factor nuclear factor interleukin 6 (NF-IL6) is known to be activated by various inflammatory stimuli in the brain. Interestingly, we recently detected NF-IL6-activation within the hypothalamus-pituitary-adrenal (HPA)-axis of rats after systemic lipopolysaccharide (LPS)-injection. Thus, the aim of the present study was to investigate whether NF-IL6 is activated during either, inflammatory, or psychological stress in the rat brain.

Methods: Rats were challenged with either the inflammatory stimulus LPS (100 $\mu \mathrm{g} / \mathrm{kg}$, i.p.) or exposed to a novel environment. Core body temperature (Tb) and motor activity were monitored using telemetry, animals were killed at different time points, brains and blood removed, and primary cell cultures of the anterior pituitary lobe (AL) were investigated. Analyses were performed using immunohistochemistry, RT-PCR, and cytokine-specific bioassays.

Results: Stress stimulation by a novel environment increased NF-IL6-immunoreactivity (IR) in the pituitary's perivascular macrophages and hypothalamic paraventricular cells and a rise in Tb lasting approximately 2 h. LPS stimulation lead to NF-IL6-IR in several additional cell types including ACTH-IR-positive corticotrope cells in vivo and in vitro. Two other proinflammatory transcription factors, namely signal transducer and activator of transcription (STAT) 3 and NFkB, were significantly activated and partially colocalized with NF-IL6-IR in cells of the AL only after LPS-stimulation, but not following psychological stress. In vitro NF-IL6-activation was associated with induction and secretion of TNFa in folliculostellate cells, which could be antagonized by the JAK-STAT-inhibitor AG490.
\end{abstract}

Conclusions: We revealed, for the first time, that NF-IL6 activation occurs not only during inflammatory LPS stimulation, but also during psychological stress, that is, a novel environment. Both stressors were associated with time-dependent activation of NF-IL6 in different cell types of the brain and the pituitary. Moreover, while NF-IL6-IR was partially linked to STAT3 and NFKB activation, TNFa production, and ACTH-IR after LPS stimulation; this was not the case after exposure to a novel environment, suggesting distinct underlying signaling pathways. Overall, NF-IL6 can be used as a broad activation marker in the brain and might be of interest for therapeutic approaches not only during inflammatory but also psychological stress.

Keywords: Nuclear factor interleukin-6, Lipopolysaccharide, Pituitary, Tumor necrosis factor a, Hypothalamic paraventricular nucleus, Novel environment-stress, STAT3, NFkB, Body temperature, Activity

\footnotetext{
* Correspondence: Christoph.D.Rummel@vetmed.uni-giessen.de

Department of Veterinary-Physiology and -Biochemistry, Justus-Liebig-University Giessen, Frankfurter Strasse 100, Giessen D-35392, Germany
} 


\section{Background}

Inflammatory transcription factors are commonly used as important brain cell activation markers during infection and inflammation to investigate immune-to-brain communication [1-7] and represent promising targets for therapeutic approaches during infectious and inflammatory insults [8-11]. However, information about the physiological role of these transcription factors for the brain during inflammatory and psychological stress is limited. As such, previous studies revealed important implications for pivotal inflammatory transcription factors including nuclear factor (NF) $\mathrm{B}$ and signal transducer and activator of transcription (STAT) 3 in fever inducing pathways $[8,10]$. In concert with endogenous pyrogens, belonging largely to the cytokine family, exogenous pathogen-associated molecular patterns derived from viruses and bacteria [2,3,12-14] lead to a characteristic transcription factor-mediated activation pattern in the brain [5,6,15], and brain inflammation. Among others, this response is linked to the induction of prostaglandindependent fever through several autonomic pathways, activating effector organs $[16,17]$.

Recently, we observed that another inflammatory transcription factor, namely NF-interleukin (IL)6, was induced in brain structures implicated in the febrile response but also in HPA (hypothalamic-pituitary-adrenal)axis activation including the median eminence (ME) and the pituitary, in a time-dependent manner. We hypothesized that it may play a role in the manifestation or even termination of fever as well as HPA-axis activity and brain inflammation [1]. This response was accompanied by the hypothalamic expression of important brain inflammatory target genes including the rate limiting enzymes in prostaglandin synthesis, for example, cyclooxygenase 2 and microsomal prostaglandin synthase.

In addition to inflammatory stimuli, such as LPS [1,18-20] or viral infections [2,21], brain NF-IL6-expression and activation/nuclear translocation were previously found to be increased in neurons during dehydration [22], in astrocytes, microglia, and neurons after kainic acid-trauma [23], via potassium chloride-induced activity of neurons [24], as neuronal response to axonal injury [25] or by neurotransmitter-induced activation of astrocytes [26]. Recently, we have also shown that brain stab-trauma increases nuclear NF-IL6-IR in the cortex [8]. Interestingly, NF-IL6 has also been implicated in excitotoxic brain injury [23], hypoxia [27], microglia-mediated neurotoxic effects [28], and memory consolidation [29] suggesting a crucial role for this inflammatory transcription factor in the brain, and specifically in brain inflammation.

Whether activation of inflammatory transcription factors also occurs during psychological stress has been previously investigated for STAT3 and NFkB $[30,31]$ but remains unknown for NF-IL6.
Here, we analyzed, for the first time, the precise spatiotemporal activation of the pivotal inflammatory transcription factor NF-IL6 during exposure to a psychological stressor, that is, a novel environment, in comparison to the inflammatory stimulus lipopolysaccharide (LPS). This study revealed a distinct activation pattern in different cell types, such that only perivascular macrophages were activated by both stimuli, but endothelial cells and corticotropes were exclusively activated by LPS stimulation. Moreover, using a primary cell culture of the anterior pituitary lobe we showed that LPS-induced NF-IL6 and STAT3 activation might be involved in TNF $\alpha$ expression by folliculostellate cells. Overall, our data illustrate the pleiotropic role of NF-IL6 in response to different types of stressors. This has important implications for therapeutic strategies, while NF-IL6-immunohistochemistry will also serve as a useful activation marker for future studies investigating inflammatory processes in the brain.

\section{Methods}

\section{Animals}

Male Wistar rats (rattus norvegicus spec.) with a body weight (BW) of $200 \pm 50 \mathrm{~g}$ or $250 \pm 50 \mathrm{~g}$ (cell cultures) were used for all experiments. The rats originated from an in-house breeding colony with parental animals obtained from Charles River WIGA (Sulzfeld, Germany). Animal care, breeding, and experimental procedures were conducted according to the guidelines approved by the local Ethics committee (ethics approval number GI 18/2 - 51/2008).

Animals were individually housed for the duration of the experiment in a climate chamber that was controlled for temperature and humidity (Weiss Umwelttechnik GmbH, Typ 10'US/+5 - +40 DU, Germany) at an ambient temperature of $25^{\circ} \mathrm{C}$ and $50 \%$ humidity on an $12: 12 \mathrm{~h}$ light-dark cycle (lights off at 19:00). Animals had constant access to water and powdered standard lab chow (ssniff Spezialdiäten GmbH Soest, Germany) and were implanted with intra-abdominal radio transmitters for measurement of core body temperature $(\mathrm{Tb})$ and motor activity suitable for rats (T-4000 E-Mitter/ER-4000 Receiver; Respironics Inc-MiniMitter, Bend, OR, USA). Implantation of transmitters was performed about 8 days before the experiment as previously reported [1], using a cocktail of ketamine hydrochloride $(50 \mathrm{mg} / \mathrm{kg}$, Pharmacia Upjohn), medetomidine (5 mg/kg, Pfizer; Albrecht), and acepromazine, $(0.5 \mathrm{mg} / \mathrm{kg}$ ) as anesthetic (i.p.). An automatic data acquisition system was used (VitalView, Respironics Inc-MiniMitter, Bend, OR, USA). Rats were handled extensively for at least 3 days prior to the experiment for habituation.

\section{Treatment and experimental protocols}

Rats were intraperitoneally (i.p.) injected with LPS $(100 \mu \mathrm{g} / \mathrm{kg}$ or $1 \mathrm{mg} / \mathrm{kg}$ BW; derived from Escherichia 
coli, serotype 0128:B12, Sigma Chemicals, Deisenhofen, Germany) diluted in sterile pyrogen-free 0.9\% PBS (Dulbecco's Phosphate Buffered Saline, PAA, D-Cölbe) at a total injection volume of $1 \mathrm{~mL}$ per animal. Control animals received the equivalent volume of PBS $(0.1 \mathrm{M}$, $\mathrm{pH}$ 7.4). All injections were performed between 09:00 and 10:00. At different time points $(2,4,8,10$, and $24 \mathrm{~h}$ p.i.) animals were euthanized by terminal anesthesia with pentobarbital (i.p.; approximately $100 \mathrm{mg} / \mathrm{kg}$, Merial $\mathrm{GmbH}$, Hallbergmoos, Germany) and transcardially perfused with ice-cold $0.9 \%$ saline.

For the novel environment-stress experiment, rats were placed into an empty cage (without any food, water, or bedding) or stayed in their original environment as a control as previously described [32]. At different time points $(30(n=3), 60(n=6), 90(n=3), 120(n=3), 240$ $(n=6) \mathrm{min}$ after stress exposure or controls after $60(n=6)$ and $240(n=6) \mathrm{min})$, rats were euthanized by terminal anesthesia and perfusion. Blood samples were collected with a sterile heparinized syringe via cardiac puncture under anesthesia. These experiments were performed between 10:00 and 14:00.

After perfusion of all animals, pituitaries and brains were quickly removed, frozen separately in powdered dry ice, and stored at $-55^{\circ} \mathrm{C}$ until analysis.

\section{Tissue processing}

Coronal $20 \mu \mathrm{m}$ brain and pituitary sections were cut on a cryostat (model HM 500, Microm, Walldorf, Germany) encompassing several hypothalamic brain structures including the subfornical organ (SFO), the hypothalamic paraventricular nucleus (PVN), the median eminence $(\mathrm{ME})$, and the pituitary (anterior lobe $(\mathrm{AL})$, intermediate lobe (IL), posterior lobe (PL)) using the stereotactic rat brain atlas of Paxinos and Watson (1998) as reference [33]. The sections were thaw-mounted on poly-L-lysine-coated glass slides and stored at $-55^{\circ} \mathrm{C}$ until processing.

\section{Immunohistochemistry}

Frozen brain sections were air-dried for $7 \mathrm{~min}$ at room temperature (RT), immersion-fixed in $2 \%$ paraformaldehyde (Merck, Darmstadt, Germany), diluted in PBS for $10 \mathrm{~min}$, and washed three times in PBS. Thereafter, the sections were incubated for $1 \mathrm{~h}$ with a blocking solution, consisting of PBS, containing 10\% normal donkey serum (NDS; Biozol, Eching, Germany) and 0.1\% triton X-100 (no triton X-100 for goat NF-IL6) at RT. Double IHC was performed for analyses of NF-IL6 immunoreactivity in endothelial cells, astrocytes, activated microglia, perivascular macrophages, and neurons. The primary antibodies (NF-IL6 or TNF $\alpha$ ) were mixed with the respective antibody to detect specific cell marker proteins (dilutions in Table 1) and sections were incubated for 20 to $22 \mathrm{~h}$ at $4^{\circ} \mathrm{C}$. After another three PBS washes, NF-IL6 was visualized with Cy3-conjugated anti-goat or anti-rabbit IgG (cat. 705-165-147 and 711-165-152, respectively; Jackson ImmunoResearch, West Grove, PA, USA). Cell-type markers were detected with Alexa-488-conjugated anti-rabbit, anti-mouse, anti-sheep, or anti-goat IgG (cat. A11055, A21202, A11015, and A11055, respectively; MoBiTec $\mathrm{GmbH}$, Goettingen, Germany) as secondary antibodies (1:500 dilution each). Subsequently, sections were incubated for 10 min with 4.6-diamidino-2-phenylindole (DAPI, 1:1,000 dilution in PBS) to stain cell nuclei (Mobitec $\mathrm{GmbH}$, Göttingen, Germany), visualize surrounding tissue, and also to demonstrate nuclear localization of NF-IL6 IR. Finally, all sections were dipped in a glycerol/PBS solution (Citifluor LTD, London, UK), cover slipped (glass cover slips), and stored (at $4^{\circ} \mathrm{C}$ ) until microscopic analysis. All primary antibodies have been used previously and proved to show specific signals $[1,34]$.

\section{Microscopical analysis}

A light/fluorescent Olympus BX50 microscope (Olympus Optical, Hamburg, Germany) was used with a black and white Spot Insight camera (Diagnostic Instruments, Visitron Systems, Puchheim, Germany) to acquire images. Digital rat brain maps were arranged for overviews by the adjustment of corresponding rat brain levels taken from the digital rat brain atlas of Paxinos and Watson (1998). Microphotographs for each set of experiment were taken in series for the relevant time points of stimulated and control sections at the same time using the same exposure time (MetaMorph 5.05 software). Image editing software was applied to combine the individual images into the RGB color figure plates (MetaMorph 5.05), to adjust brightness and contrast for better representation and to store the images as TIFF files (Adobe Photoshop 5.05).

\section{Semi-quantitative analysis of nuclear NF-IL6 immunoreactivity}

Relative values of nuclear NF-IL6 immunoreactivity are presented as estimates for the density of their labeling. Three (PVN, pituitary), one to three (SFO), or two to four (LPS stimulation, pituitary) sections per animal for three to six animals per group were analyzed (Tables 2 and 3 ). Evaluation was directly performed for each set of experiment at the same time. A five-point scale was used to rate the data as means ( 2 to 4 sections) of the means ( 3 to 6 animals): +++ (5), high density of nuclear signals; ++ (4), moderate density; + (3), low density; \pm (2), single nuclear signals in some cases; and - (1) no nuclear signals.

\section{Primary cell culture of the anterior lobe of the pituitary}

For each preparation two to three animals were quickly decapitated with a guillotine and the heads were immersed ( $<20 \mathrm{~s}$ ) in ice-cold 0.1 M phosphate-buffered saline (PBS; 
Table 1 Dilutions for the primary antibodies used for immunohistochemistry or immunocytochemistry

\begin{tabular}{llll}
\hline Antigen & Species, type & Dilution & Catalog number, manufacturer \\
\hline NF-IL6 & Goat polyclonal lgG & $1: 250$ & cat. sc-150-G; Santa Cruz Biotechnology, Santa Cruz, CA, USA \\
NF-IL6 & Rabbit polyclonal lgG & $1: 9000$ & cat. sc-150; Santa Cruz Biotechnology, Santa Cruz, CA, USA \\
STAT3 & Rabbit polyclonal lgG & $1: 8000$ & cat. sc-21876; Santa Cruz Biotechnology, Santa Cruz, CA, USA \\
NFkB & Goat polyclonal lgG & $1: 500$ & cat. sc-372; Santa Cruz Biotechnology, Santa Cruz, CA, USA \\
WWF & Sheep polyclonal lgG & $1: 3000$ & cat. SARTW-IG; Affinity Biologicals, Ancaster, Canada \\
GFAP & Mouse monoclonal lgG & $1: 2000$ & cat. MAB3402; Millipore, Billerica, MA, USA \\
CD68 (ED1) & Mouse monoclonal lgG & $1: 1000$ & cat. MCA341R; AbD Serotec, Oxford, United Kingdom \\
CD163 (ED2) & Mouse monoclonal lgG & $1: 500$ & cat. MCA342R; AbD Serotec, Oxford, United Kingdom \\
NOS1 & Rabbit polyclonal lgG & $1: 500$ & cat. sc-648; Santa Cruz Biotechnology, Santa Cruz, CA, USA \\
ACTH (1-24) & Rabbit polyclonal lgG & $1: 2000$ & Gift from Dr. Blähser, Institute of Anatomy and Cytobiology, JLU Giessen, Germany (Blähser, 1988) \\
Anti- S100 & Rabbit polyclonal lgG & $1: 250$ & cat. S2644 Sigma-Aldrich, Munich, Germany \\
TNFa & Goat polyclonal lgG & $1: 2000$ & cat. AF-510-NA R\&D Systems, MN, USA \\
\hline
\end{tabular}

PAA Laboratories GmbH, Coelbe, Germany), pH 7.4. Each pituitary was immediately removed from the skull under low-germ/almost sterile conditions and placed into an ice-cold Petri dish with oxygenated Earle's Balanced Salt Solution (EBSS; Invitrogen, Darmstadt, Germany). The anterior lobe of the pituitary was removed and placed into a Petri dish filled with ice-cold, oxygenated Hanks Balanced Salt Solution (HBSS) without $\mathrm{Ca}^{2+}$ and $\mathrm{Mg}^{2+}$ (Biochrom, Berlin, Germany), but supplemented with $20 \mathrm{mM}$ HEPES (Sigma-Aldrich), pH 7.4. Pituitary fragments were then treated with $2 \mathrm{mg} / \mathrm{mL}$ dispase-1 (Roche Diagnostics, Mannheim, Germany) in oxygenated HBSS with $20 \mathrm{mM}$ HEPES, pH $7.4\left(90 \mathrm{~min}\right.$ at $\left.37.0^{\circ} \mathrm{C}\right)$. After, the pituitary fragments were washed once with HBSS containing $1.0 \mathrm{mM}$ EDTA (Sigma-Aldrich) to inactivate the enzyme, then washed three times with complete medium, consisting of Dulbecco's Modified Eagle Medium (DMEM; Invitrogen, Darmstadt, Germany) supplemented with 10.0\% FCS (PAA Laboratories GmbH, Coelbe, Germany), penicillin (100 U/mL), streptomycin $(0.1 \mathrm{mg} / \mathrm{mL}$ ), and $4 \mathrm{mM} \mathrm{L}$-glutamine (Biochrom AG, Berlin, Germany). Finally, tissue was mechanically dissociated in $2.0 \mathrm{~mL}$ complete medium by repeated trituration with a $1 \mathrm{~mL}$ Eppendorf pipette tip. After cell number determination, cells were diluted to approximately
250,000 cells per $\mathrm{mL}$ and plated onto prewarmed, polyL-lysine $(0.1 \mathrm{mg} / \mathrm{mL}$; Biochrom AG, Berlin, Germany)coated glass coverslips (MAGV GmbH, Rabenau, Germany) forming the bottom of a reusable Flexiperm-micro-12 well (6 mm diameter; Greiner Bio-One $\mathrm{GmbH}$, Solingen, Germany) to ensure sufficient cell density despite limited absolute cell number. Cells were cultured in a humidified atmosphere of $5 \% \mathrm{CO} 2$ and $95 \%$ air at $37.0^{\circ} \mathrm{C}$. The medium was exchanged the next day to remove cellular debris. Two days later, the culture medium was exchanged with serum-free culture medium to prevent potentially stimulatory effects by its components and experiments were performed the next day. Cell culture conditions were chosen according to in-house procedures for primary neuro-glial cell cultures of the circumventricular organs [35] and adjusted to protocols for primary pituitary cell cultures, previously utilized by others [36-38]. For each experiment, relative cell density was controlled after immunohistochemical staining (5 predefined areas counted; mean of approximately 500 cells).

\section{Treatment protocols}

Cells were stimulated with LPS $(100 \mu \mathrm{g} / \mathrm{mL})$ or PBS and incubated for $6 \mathrm{~h}$. According to a preliminary time course experiment (data not shown) and results from other

Table 2 Semi-quantitative analyses of nuclear NF-IL6 immunoreactivity after novel environment stress (stress)

\begin{tabular}{|c|c|c|c|c|c|c|c|}
\hline \multirow{3}{*}{$\begin{array}{l}\text { Brain } \\
\text { structure }\end{array}$} & \multicolumn{7}{|c|}{ Time (min) } \\
\hline & \multicolumn{5}{|c|}{ Stress } & \multicolumn{2}{|c|}{ Control } \\
\hline & 30 & 60 & 90 & 120 & 240 & 60 & 240 \\
\hline SFO & $++(3.7)$ & $+(2.7)$ & $++(3.7)$ & $+(3.0)$ & $+(3.3)$ & $+(3.0)$ & $\pm(2.4)$ \\
\hline PVN & $\pm(2.3)$ & $+(3.4)$ & $++(4.2)$ & $++(4.3)$ & $\pm(2.2)$ & $\pm(2.2)$ & $\pm(2.0)$ \\
\hline Pituitary & $+(3.3)$ & $++(4.3)$ & $+++(5.0)$ & $+(2.7)$ & $+(2.6)$ & $+(3.0)$ & $\pm(2.3)$ \\
\hline
\end{tabular}

Semi-quantitative analysis of the amount of nuclear NF-IL6 signals in the subfornical organ (SFO), in the hypothalamic paraventricular nucleus (PVN), and in the anterior lobe of the pituitary gland (pituitary) of rats 30,60, 90, 120, and 240 min after stress or 30 and 240 min after a control situation (undisturbed). A five-point scale was used to rate the data: $+++(5)$, high density of nuclear signals; $++(4)$, moderate density of nuclear signals; $+(3)$, low density; $\pm(2)$, single nuclear signals in some cases; - (1), no nuclear signals. 
Table 3 Semi-quantitative analysis of LPS-induced nuclear NF-IL6 immunoreactivity

\begin{tabular}{|c|c|c|c|}
\hline Time (h) & $100 \mu \mathrm{g} / \mathrm{kg}$ LPS & $1 \mathrm{mg} / \mathrm{kg}$ LPS & Control (saline) \\
\hline \multicolumn{4}{|c|}{$\begin{array}{l}\text { Anterior lobe of the pituitary } \\
\begin{array}{ll}2 \\
+(3.0)\end{array}\end{array}$} \\
\hline 4 & $++(4.4)$ & & \\
\hline 8 & $+++(5.0)$ & $+++(4.6)$ & $\pm(2.0)$ \\
\hline 10 & $++(4.4)$ & & \\
\hline 24 & $\pm(2.0)$ & $\pm(2.4)$ & \\
\hline \multicolumn{4}{|c|}{ Posterior lobe of the pituitary } \\
\hline 2 & $\pm(2.0)$ & & \\
\hline 4 & $++(4.1)$ & & \\
\hline 8 & $+++(4.8)$ & $++(3.9)$ & $\pm(2.0)$ \\
\hline 10 & $++(4.2)$ & & \\
\hline 24 & $\pm(2.0)$ & $\pm(2.2)$ & \\
\hline
\end{tabular}

Semi-quantitative analysis of the number of nuclear NF-IL6 signals in the anterior lobe and the posterior lobe of the rat pituitary $2,4,8,10$, and $24 \mathrm{~h}$ after injection of $100 \mathrm{ug} / \mathrm{kg}$ LPS or 8 and $24 \mathrm{~h}$ after the injection of $1 \mathrm{mg} / \mathrm{kg}$ LPS compared to controls ( $8 \mathrm{~h}$ after injection of saline). A five-point scale was used to rate the data: $+++(5)$, high density of nuclear signals; $++(4)$, moderate density of nuclear signals; + (3), low density; \pm (2), single nuclear signals in some cases; - (1), no nuclear signals.

primary cell cultures, $6 \mathrm{~h}$ proved to be an ideal time point to detect TNFa immunreactivity and its release (16 independent experiments) into the supernatant [39]. In another set of experiments (3 independent experiments, 2 to 3 wells for each treatment), the JAK-STAT-inhibitor AG 490 (N-Benzyl-3,4-dihydroxybenzylidenecyano-acetamide; $1,5 \mu \mathrm{g} / \mu \mathrm{L}, 5 \mathrm{mM}$; Enzo Life Sciences International Inc., PA, USA) or its diluent (25\% Cremophor ${ }^{\circ} E L$, Polyoxyethylenglyceroltriricinoleat 35 , DAC in PBS; into serum-free medium 1:50; Sigma-Aldrich, Munich, Germany) were used to preincubate cells $30 \mathrm{~min}$ before control or LPS stimulation. The cells of the anterior lobe of the pituitary were fixed with $4 \%$ freshly prepared paraformaldehyde (Merck) in PBS, pH 7.4, for 15 min at RT and immunocytochemistry was performed as previously reported [39] using the same antibodies and dilutions as indicated in Table 1. Supernatants were used for the determination of TNF $\alpha$.

\section{Quantification of ACTH-immunoreactive cells}

To investigate the effects of LPS treatment and AG490 pretreatment on the number of ACTH-IR cells we quantified the number of cells in five equal areas using a conventional ocular counting grid. The selection of the areas was standardized: in the middle and on the four outer edges of the cell coated cover slips. First, all $\mathrm{ACTH}$-positive cells and second the total number of DAPI-positive cell nuclei were counted. Data were then calculated as percentage of ACTH-positive cells out of all cells counted for one experiment. Finally, the mean percentage of ACTH-positive cells out of three independent experiments was calculated and used for blotting the data and for statistical analyses.

\section{Plasma IL- 6 and TNFa measurements}

IL- 6 and TNF $\alpha$ levels were determined by bioassays. The IL- 6 assay is based on a dose-dependent growth stimulation by IL- 6 on the B9 hybridoma cell line. For the TNF $\alpha$-bioassay the cytotoxic effect of TNF $\alpha$ on the mouse fibrosarcoma cell line WEHI 164 subclone 13 was used as previously reported [2]. The detection limit of the assay after adjustment for assays dilutions of samples was 3 international units (IU) for $\mathrm{IL}-6 / \mathrm{mL}$ and $6.0 \mathrm{pg} / \mathrm{mL}$ for TNF $\alpha$. TNF $\alpha$ levels in primary cell culture supernatants of anterior rat pituitaries were measured for three independent experiments with 2 to 3 wells for each treatment and adjusted to the relative cell density in percentage to LPS and cremophor-stimulated samples.

\section{Data analysis}

Abdominal temperatures (at 5-min time intervals) and cumulative motor activity (cumulative over 15 min periods) were compared by a two-way repeated measures analysis of variance (ANOVA) followed by an all pairwise Tukey multiple comparison post-hoc test (SIGMA Stat ${ }^{\circ}$; Systat Software, Inc., Point Richmond, CA, USA.). Circulating levels of bioactive IL-6, TNF $\alpha$, ACTH-positive cells, and cumulative motor activity over $240 \mathrm{~min}$ were compared by ANOVA followed by Newman-Keuls multiple comparison post-hoc test (GraphPad Prism 5 software; San Diego, CA, USA). $P<0.05$ was considered statistically significant. All data are presented as means \pm SEM.

\section{Results}

Psychological stress induces hyperthermia, hyperlocomotion, and increased NF-IL6-IR

Psychological stress induced an increase in $\mathrm{Tb}$ from 30 to $120 \mathrm{~min}$ (Figure $1 \mathrm{~A}, P<0.05$; mean increase $1.03 \pm$ $0.19 \mathrm{C}$; stress $v s$. control) and an increase in locomotor activity from 30 to $90 \mathrm{~min}$ (Figure $1 \mathrm{~B}, P<0.05$ ), as previously reported [32]. Plasma IL-6 levels did not increase over time in the stressed animals (Figure 1C, one way ANOVA).

These effects were accompanied by increased novel environment stress-induced nuclear NF-IL6-IR that peaked between 90 and $120 \mathrm{~min}$ in the PVN (Additional file 1E,F) and between 60 and $90 \mathrm{~min}$ in the pituitary (Figure 2D,E) but was unchanged in other brain structures such as the SFO (Table 2). NF-IL6-IR appeared to be particularly strong lining the intermediate lobe and in the anterior pituitary lobe compared to untreated controls (Figure 2A-G). A semi-quantitative five-point scale evaluation of two sections per rat for three or six (for 60 and $240 \mathrm{~min}$ ) animals per group confirmed these qualitative observations (Table 2). In this stress paradigm no NF-IL6- 


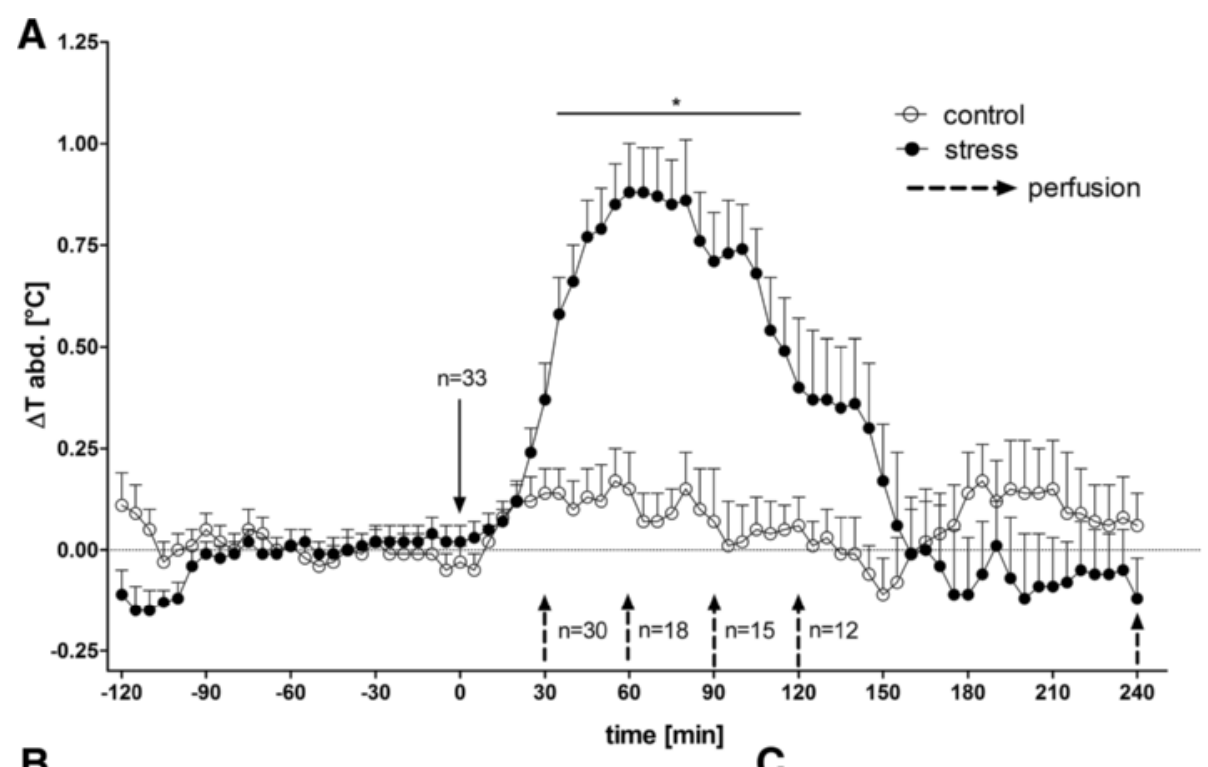

B

C
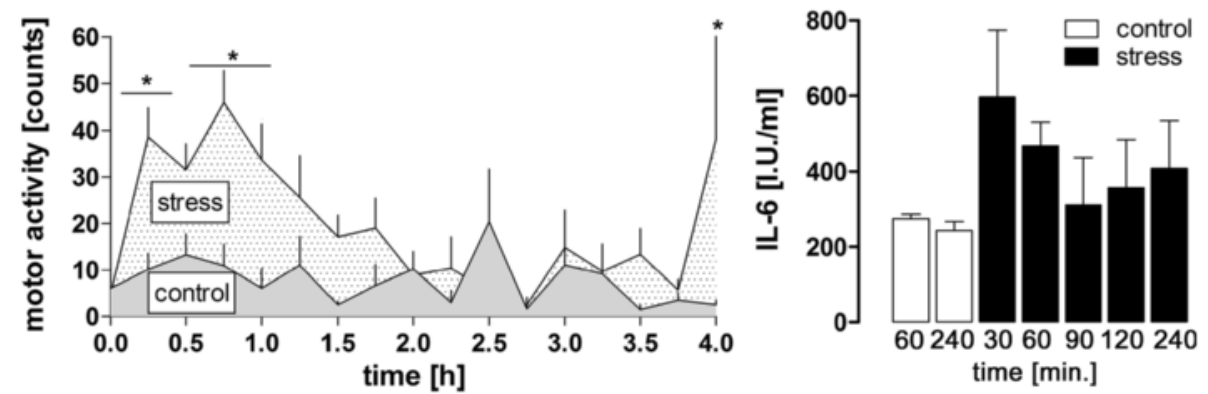

Figure $1 \mathrm{~Tb}$, motor activity, and plasma IL-6 levels during novel environment stress or control situation in rats. (A) Novel environment stress (stress) induced a rise in body temperature (Tb). (B) This response was preceded and accompanied by increased motor activity (averaged cumulative activity over 15 min for each) but (C) no significant rise in plasma interleukin 6 (IL-6)-levels, when compared over time to unstressed control animals. Dashed black arrows indicate changes in the number of animals; this number of animals reduces with time because of animal groups being perfused at the indicated time points. $n=3(30,90$, and $120 \mathrm{~min}$ ) or 6 (60 and $240 \mathrm{~min}$ ) for each group of perfusion (stress; control only for 60 and $240 \mathrm{~min}$ ). For IL-6 $n=3$ or 6 (60 and $240 \mathrm{~min}$ ) samples were analyzed ${ }^{*} P<0.05$.

positive corticotropes (Figure 3A,B), pituicytes (Figure 3C, D, GFAP), or endothelial cells (Figure 3E,F, VWF) could be observed. Nonetheless, some NF-IL6-IR positive cells colocalized with CD163-stained perivascular macrophages in both the anterior and the posterior pituitary lobe in stressed (Figure 3H) but not control animals (Figure 3G). Neither increased activation of STAT3 nor NFkB could be observed in brains and pituitaries of these animals (data not shown).

\section{LPS induced NF-IL6 IR in pituitary corticotropes and other cell phenotypes}

Systemic LPS stimulation $(100 \mu \mathrm{g} / \mathrm{kg})$ induced increased NF-IL6-IR in the posterior and anterior pituitary lobe of rats (Figure 4A-C and E-G) compared to saline injected controls (Figure 4D). This IR started to increase at $4 \mathrm{~h}$ (Figure $4 \mathrm{C}$ ) and peaked in its intensity and cell density
$8 \mathrm{~h}$ after the LPS challenge (Figure 4A and E) followed by a decline after the $10 \mathrm{~h}$ (Figure $4 \mathrm{~F}, \mathrm{G}$ ) to basal NF-IL6-IR (Table 3). Interestingly, the magnitude of this response was not altered, at 8 and $24 \mathrm{~h}$, when a $10 \times$ higher dose of LPS was injected $(1 \mathrm{mg} / \mathrm{kg}$, Figure $4 \mathrm{H}, \mathrm{I})$. While the intermediate pituitary lobe did not show any NF-IL6-IR, particular strong NF-IL6-IR was observed lining its junctions with both the anterior and the posterior lobe, as can be observed in the overview and higher magnifications of Figures 4 and 5. Semi-quantitative five-point scale evaluation of two to four sections per rat for three animals per group confirmed these qualitative observations (Table 3). Figure 5 shows co-localization of several cell marker proteins with NF-IL6-IR in pituitary sections of LPS- compared to saline-stimulated animals $8 \mathrm{~h}$ after injection. We revealed some ACTH-IR positive corticotropes (Figure 5Bc) in the anterior and GFAP-IR positive pituicytes (Figure $5 \mathrm{Ca}$ and $\mathrm{Da}$ ) in the posterior 

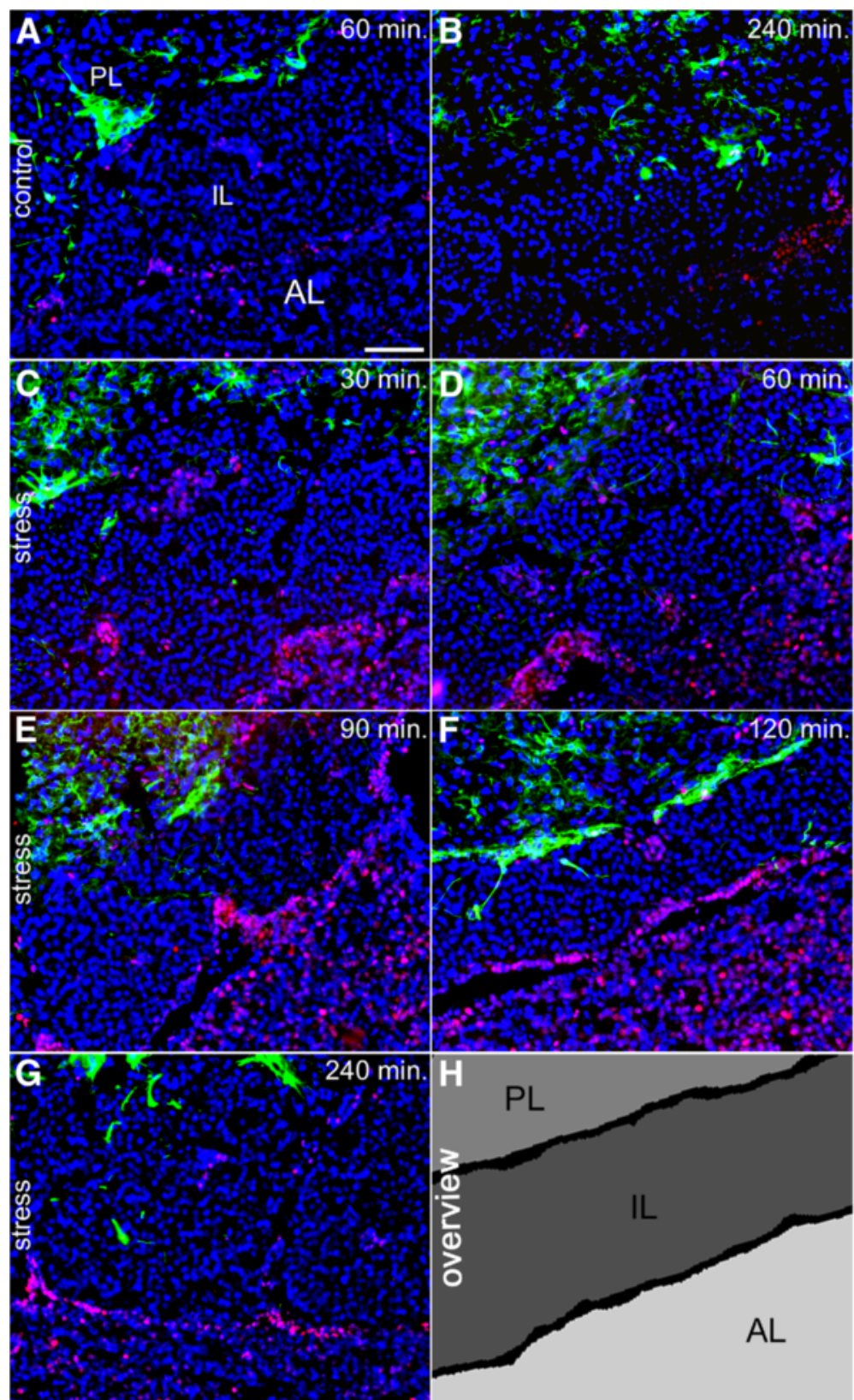

Figure 2 Novel environment stress (stress) induced a significant increase in nuclear NF-IL6-IR in the pituitary of rats. (A, B) Some nuclear (DAPI, blue) NF-IL6-IR (red) can be observed in unstimulated control animals. (C-F) After novel environment-stress was introduced, nuclear NF-IL6-IR peaked (D, E) 60 to 90 min later and (G) declined to control levels at $240 \mathrm{~min}$. GFAP detection (green) was used to better visualize the posterior pituitary lobe. $(\mathbf{H})$ The schematic overview clearly depicts the substructure of microphotographs, containing all pituitary lobes (anterior lobe (AL), intermediate lobe (IL), and posterior lobe (PL)). Brightness, contrast, and color balance were adjusted for better representation of the actual data. The scale bar in $\mathbf{A}$ represents $100 \mu \mathrm{m}$ (applies to $\mathbf{A}-\mathbf{G}$ ).

lobe co-localized with nuclear NF-IL6-IR. Endothelial cells (von Willebrand factor, VWF-positive cells) showed NF-IL6-IR-positive nuclei in all parts of the pituitary (Figure 5Fa-c), whereas nNOS positive cells co-localized with NF-IL6-IR only in the posterior lobe (Figure 5Ha). Moreover, CD163 or CD68 positive cells, indicative of the appearance of perivascular macrophages or activated mac- rophages, respectively, showed nuclear NF-IL6-IR in the anterior and posterior lobe (Figure 5I-L, a and c for each).

\section{LPS-induced nuclear NF-IL6-IR partly co-localizes with STAT3 or NFKB-IR in the posterior pituitary lobe} Inflammatory transcription factors are known to interact and influence transcriptional activity among each other 


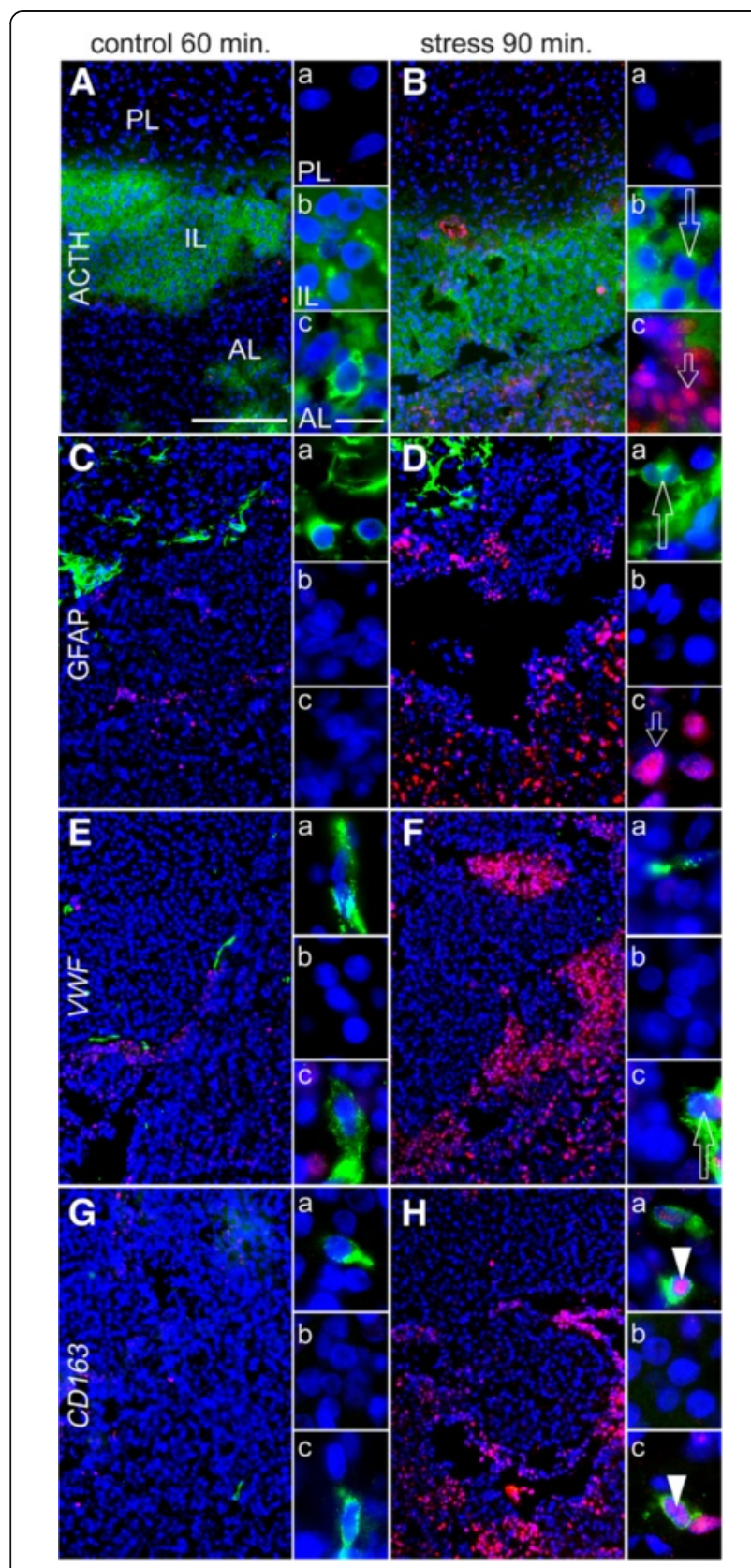

Figure 3 Novel environment stress (stress) induced nuclear NF-IL6IR that co-localizes with CD163-positive perivascular macrophages in the rat pituitary. NF-IL6-IR (red) was co-localized with specific cell marker proteins (green) after novel environment-stress (90 min) or in unstimulated control animals (60 min). (A-H) Stress-induced nuclear NF-IL6-IR was not co-localized in corticotrope cells (ACTH; A, B), astrocytes (GFAP; C, D), endothelial cells (MWF; E, F) but in perivascular macrophages $(C D 163 ; \mathbf{H})$ of the anterior $(A L$, c) and posterior pituitary lobe $(\mathrm{PL}, \mathbf{a})$. Insets (a-c) show high magnifications of the PL, IL, and AL, respectively. Open arrows represent either NF-IL6-IR-negative cells of identified phenotype or some NF-IL6-IR cells of unidentified phenotype (green). White arrow tips show nuclear NF-IL6-IR in perivascular macrophages. Cell nuclei were labeled with DAPI (blue). Brightness, contrast, and color balance were adjusted for better representation of the actual data. The scale bar in $\mathbf{A} 100 \mu \mathrm{m}$ (applies to $\mathbf{A}-\mathbf{H}$ ) and $10 \mu \mathrm{m}$ for all insets (a-c).
[40]. Thus, NF-IL6-IR (Figure 6Aa1-Bb1) was co-localized with STAT3 (Figure 6A) and NFkB-IR (Figure 6B) in the pituitary of rats $2 \mathrm{~h}(\mathrm{NFkB}$, Figure 6b2-b3) or $4 \mathrm{~h}$ (STAT3, Figure 6a2-a3) after LPS stimulation. As previously reported, nuclear STAT3-IR and NFkB-IR were detected all over the pituitary gland excluding the intermediate lobe for NFkB [41,42]. Indeed, NF-IL6-IR co-localized with both transcription factors in the anterior lobe of the pituitary. While some cells only showed NF-IL6-IR, but no STAT3-IR, we did not detect cells that only showed STAT3-IR without NF-IL6-IR (Figure 6a3). As for NFkB-IR, co-localization was detected with either strong or very weak NF-IL6-IR (Figure 6b3). Overall, some NF-IL6-IR in pituitary cells was clearly detected in co-localization with STAT3/NFKB but also without such a co-localization. Novel environment stress did not significantly induce STAT3 or NFKB-IR in the brain (data not shown), although this had previously been reported to be the case after foot shock for STAT3 [31] or restraint stress for NFKB [30]. This most likely was due to the much more moderate stress response to a novel environment in the present study.

\section{LPS-induced NF-IL6-IR in corticotropes is linked to TNFa} induction and release from folliculostellate cells mediated by JAK-STAT3 activation

LPS-induced NF-IL6-IR in corticotrope cells of the anterior pituitary lobe was confirmed $6 \mathrm{~h}$ after LPS stimulation of primary pituitary cell cultures (Figure 7a, representative microphotographs out of 16 independent experiments) compared to PBS controls (Figure 7A). This activation was linked to LPS-increased TNF $\alpha$-IR in S100-postive folliculostellate cells (Figure 7b) and its release into the supernatant of the primary cell cultures (Figure 7E). Pretreatment with the JAK-STAT inhibitor AG490 (100 $\mu \mathrm{M}, 30 \mathrm{~min}$ before) drastically reduced LPS-induced NF-IL6-IR (Figure 7c,d) and TNF $\alpha$ secretion into the supernatants (Figure 7E), suggesting a role for this signaling pathway for NF-IL6-activation and TNFa production and/or release $\left(F_{3,24}=593.3, \quad P<0.001\right.$; AG490 LPS vs. Crem LPS; Crem PBS vs. Crem LPS; one-way ANOVA followed by Newman-Keuls multiple comparison test). Moreover, AG490 treatment in LPSstimulated pituitary cells significantly increased the percentage of ACTH-positive cells compared to solvent pretreated (Crem LPS) and control cultures (Crem PBS, AG490 PBS) (Figure 7F; $F_{3,24}=9.309 ; P<0.001$, AG490 LPS vs. AG490 PBS; $P<0.01$, AG490 LPS $v s$. Crem PBS, AG490 LPS vs. Crem LPS; one-way ANOVA followed by Newman-Keuls multiple comparison test).

\section{Discussion}

In the current study we revealed for the first time that the inflammatory transcription factor NF-IL6 is activated 

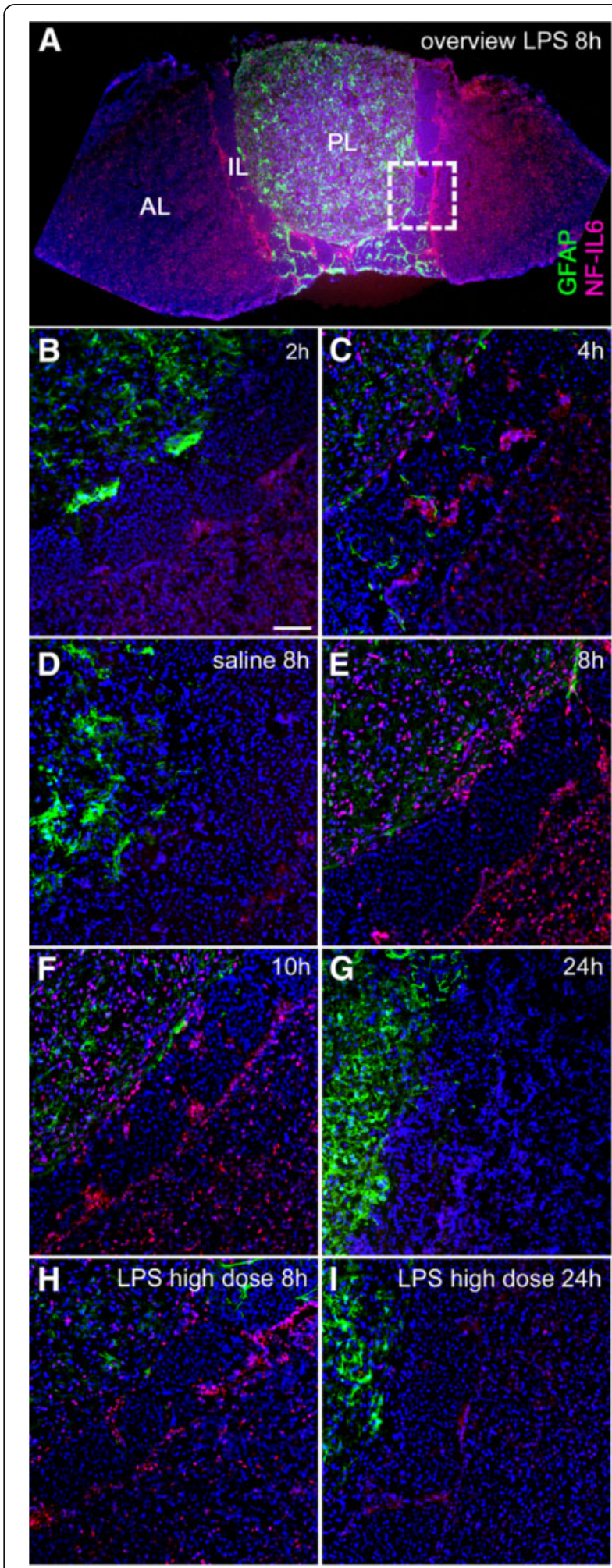

Figure 4 Time course of LPS-induced NF-IL6-IR (red) in the rat pituitary. (A) An overview shows typical NF-IL6-IR distribution $8 \mathrm{~h}$ after LPS stimulation in the anterior (AL), intermediate (IL), and posterior pituitary lobe $(\mathrm{PL})$. The dashed square indicates respective localization of the following microphotographs at higher magnification. (B-G) LPS stimulation (100 $\mu \mathrm{g} / \mathrm{kg}$ i.p.) induced NF-IL6-IR, which peaked $8 \mathrm{~h}$ after injection (E). Some NF-IL6-IR was also observed $8 \mathrm{~h}$ after saline injection (D), which was similar to levels $24 \mathrm{~h}$ after LPS stimulation (G). (H, I) When injecting a $10 \times$ higher LPS dose (1 mg/kg i.p.), the amount of NF-IL6-IR was not further increased at respective time points ( 8 and $24 \mathrm{~h}$ ) compared to sections of animals that were stimulated with $100 \mu \mathrm{g} / \mathrm{kg}$ LPS i.p. (D, E). Please note overall strong NF-IL6-IR lining the IL. Cell nuclei were labeled with DAPI (blue) and pituicytes with GFAP (green) for better visualization of the surrounding tissue. Brightness, contrast, and color balance were adjusted for better representation of the actual data. Scale bar in B represents $100 \mu \mathrm{m}$ and applies to B-I.

not only in the pituitary after in vivo or in vitro stimulation with the inflammatory stimulus LPS, but also by novel environment stress in the PVN and the anterior and posterior pituitary lobe. Moreover, our present results further broaden the application portfolio for NF-IL6 as an activation marker, useful for a variety of research questions ranging from LPS inflammation to psychological stress models.

Interestingly, spatiotemporal analyses of NF-IL6-IR cellular phenotypes revealed differences between both types of stressors. On one hand, the time course of NF-IL6-IR was different (peak at $8 \mathrm{~h}$ for LPS vs. approximately $90 \mathrm{~min}$ for psychological stress). On the other, while NF-IL6-IR in perivascular macrophages was detected in both psychological and immune stress, LPS stimulation selectively induced NF-IL6 in pituicytes, nNOS-postive cells, endothelial cells, and corticotropes. In addition, LPS-induced NF-IL6-IR partially co-localized with NFkB and STAT3, and was linked to LPS-induced TNF $\alpha$-IR in folliculostellate cells of the anterior pituitary lobe and its release in primary pituitary rat cell cultures. In contrast, the novel environment-induced NF-IL6 was not linked to the appearance of other inflammatory transcription factors.

A hallmark of immune-to-brain communication during infection, inflammation, and psychological stress is the concomitant activation of the HPA-axis [43]. First, corticotropin-releasing hormone $(\mathrm{CRH})$ from parvocellular neurons of the hypothalamic paraventricular nucleus (PVN) is released at the level of the median eminence (ME). Second, CRH acts via the portal system on corticotrope cells in the anterior lobe of the pituitary that secrete adrenocorticotrope hormone (ACTH). Third, $\mathrm{ACTH}$ induces an increase of corticosteroids in the circulation derived from the adrenal cortex. Overall, this response acts as a negative feedback mechanism, primarily toning down the immune response and limiting HPA-axis activation [44]. 


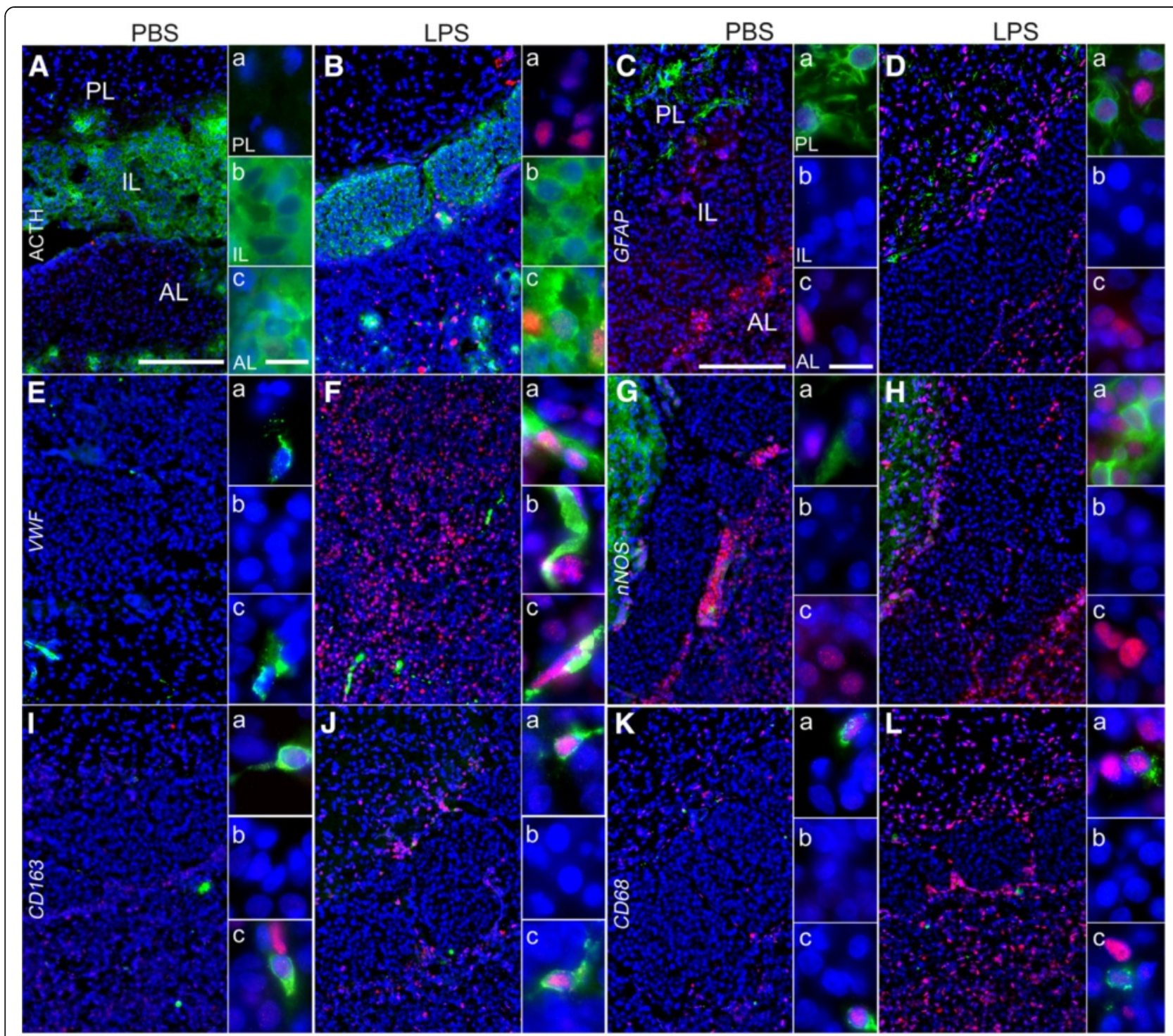

Figure 5 Cellular phenotypes showing lipopolysaccharide (LPS)-induced NF-IL6-IR in the rat pituitary $8 \mathbf{~ h}$ after stimulation. NF-IL6-IR (red) was co-localized with specific cell marker proteins (green) after LPS (100 $\mu \mathrm{g} / \mathrm{kg}$ i.p.) or PBS stimulation. (A-L) LPS-induced NF-IL6-IR occurred in corticotrope cells (ACTH, B), pituicytes (GFAP, D), endothelial cells (WWF, F), neuronal nitric oxide synthase-expressing neurons (nNOS, $\mathbf{H})$, perivascular macrophages $(C D 163, \mathbf{J})$, and activated macrophages (CD68, L) in the rat pituitary. PBS-treated controls also exhibited NF-IL6-IR in pituicytes (C), nNOS-expressing neurons (G), perivascular macrophages (I), and activated macrophages $(\mathbf{K})$ to a certain extent. Please note that representative microphotographs depict only very few NF-IL6-IR cells in the intermediate lobe (IL), including endothelial cells (b). Insets (a-c) show high magnifications of the PL, IL, and AL, respectively. Cell nuclei were labeled with DAPI (blue). Brightness, contrast, and color balance were adjusted for better representation of the actual data. The scale bars in $\mathbf{A}$ and $\mathbf{C}$ represent $100 \mu \mathrm{m}$ (applies to $\mathbf{A}-\mathbf{L}$ ) and $10 \mu \mathrm{m}$ in all insets (applies to $\mathbf{a}-\mathbf{c}$ ). AL, anterior lobe; IL, intermediate lobe; PL, posterior lobe.

Previously, the inflammatory transcription factors STAT3 and $\mathrm{NFKB}$ have been implicated in HPA-axis activation $[30,31,41,42,45,46]$. Moreover, STAT3, NFkB, and NF-IL6 have been implicated in proopiomelanocortin (POMC, precursor of $\mathrm{ACTH}$ ) and $\mathrm{CRH}$-expression [45-48]. Here, we observed NF-IL6 activation in specific cell types that, in part, co-localized with ACTH immunoreactivity (IR) in the pituitary during LPS-induced inflammation, both in vivo and in vitro. This observation supports the presumption of a contribution of NF-IL6 in POMC/ ACTH expression. However, NF-IL6-IR peaked at a much later time point after LPS (pituitary, 6 to $8 \mathrm{~h}$ ) or novel environment stress (pituitary, 60 to $90 \mathrm{~min}$; PVN, 90 to $120 \mathrm{~min}$ ) than expected for its potential role in HPA-axis activation. This stress response starts 15 to $30 \mathrm{~min}$ after the inflammatory (LPS, $25 \mu \mathrm{g} / \mathrm{kg}$ ) [49] or the 

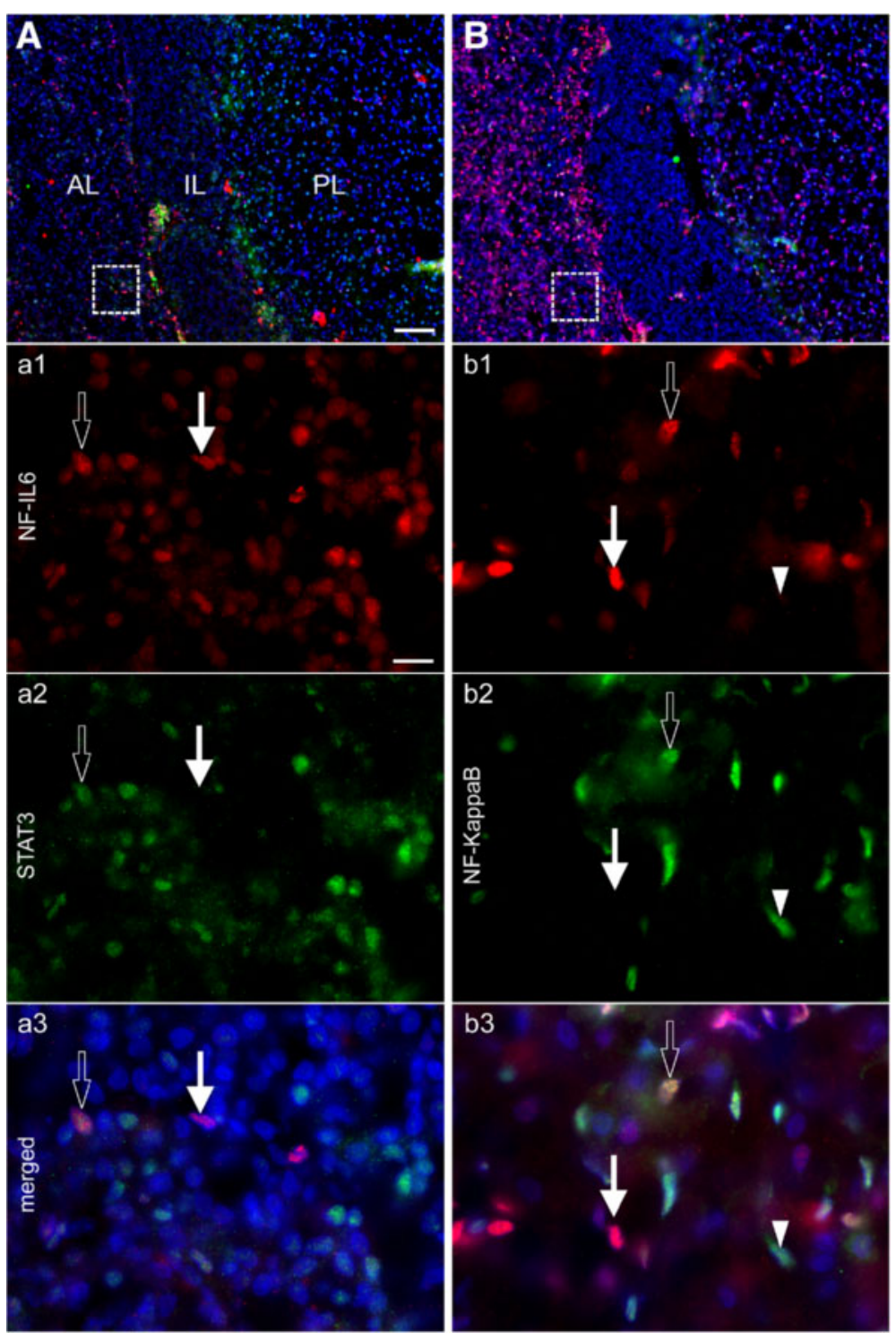

Figure 6 Co-localization of nuclear NF-IL6-IR with NFKB- or STAT3-IR 2 or $4 \mathrm{~h}$ after LPS-stimulation. (A, B) The overviews depict the neuroanatomical structure and distribution pattern of IR in the anterior lobe (AL), the intermediate lobe (IL), and the posterior lobe (PL) of the rat pituitary. Dashed squares indicate the localization of high magnification (a, b). LPS (100 $\mu \mathrm{g} / \mathrm{kg}$ i.p.) induced nuclear (DAPI, blue) NF-IL6-IR (red), which shows some co-localization with both STAT3- and NFKB-IR (both green) as indicated by open arrows in single channels $\left(\mathbf{a}_{1-2}-\mathbf{b}_{1-2}\right)$ and the merged overlay $\left(\mathbf{a}_{\mathbf{3}}-\mathbf{b}_{\mathbf{3}}\right) 2$ (NFKB) or $4 \mathrm{~h}$ (STAT3) after stimulation, respectively. Moreover, nuclear NF-IL6-IR can also be seen without co-localization (white arrows) and some single nuclear NFKB-IR occurred with only very weak co-localization with NF-IL6-IR (white arrow tips). Brightness, contrast, and color balance were adjusted for better representation of the actual data. Scale bar in A represents $100 \mu \mathrm{m}$ (applies to A, B), $10 \mu \mathrm{m}$ in $\mathrm{a}_{1}$ and applies to $\mathbf{a}_{1-3}$ and $\mathbf{b}_{1-3}$

psychological stimulus [50] and returns to baseline 480 or $120 \mathrm{~min}$ after the respective stimulation. Therefore, if NFIL6 is involved in this response, it may contribute to a late phase of maintained activation in the pituitary or even its termination. Interestingly, NF-IL6-IR did not co-localize with ACTH IR after psychological stress, indicating that the link between NF-IL6 and the stress axis might not directly involve NF-IL6-mediated ACTH expression. The precise mechanisms remain to be investigated in more detail in the future.

With regard to the effects of psychological stress and the increase in $\mathrm{Tb}$, it remains controversial whether it represents a true fever (for example, a change in the thermoregulatory balance point [51] that is accompanied by an active thermoregulatory response) as opposed to a passive increase of $\mathrm{Tb}$, termed hyperthermia. In favor of 


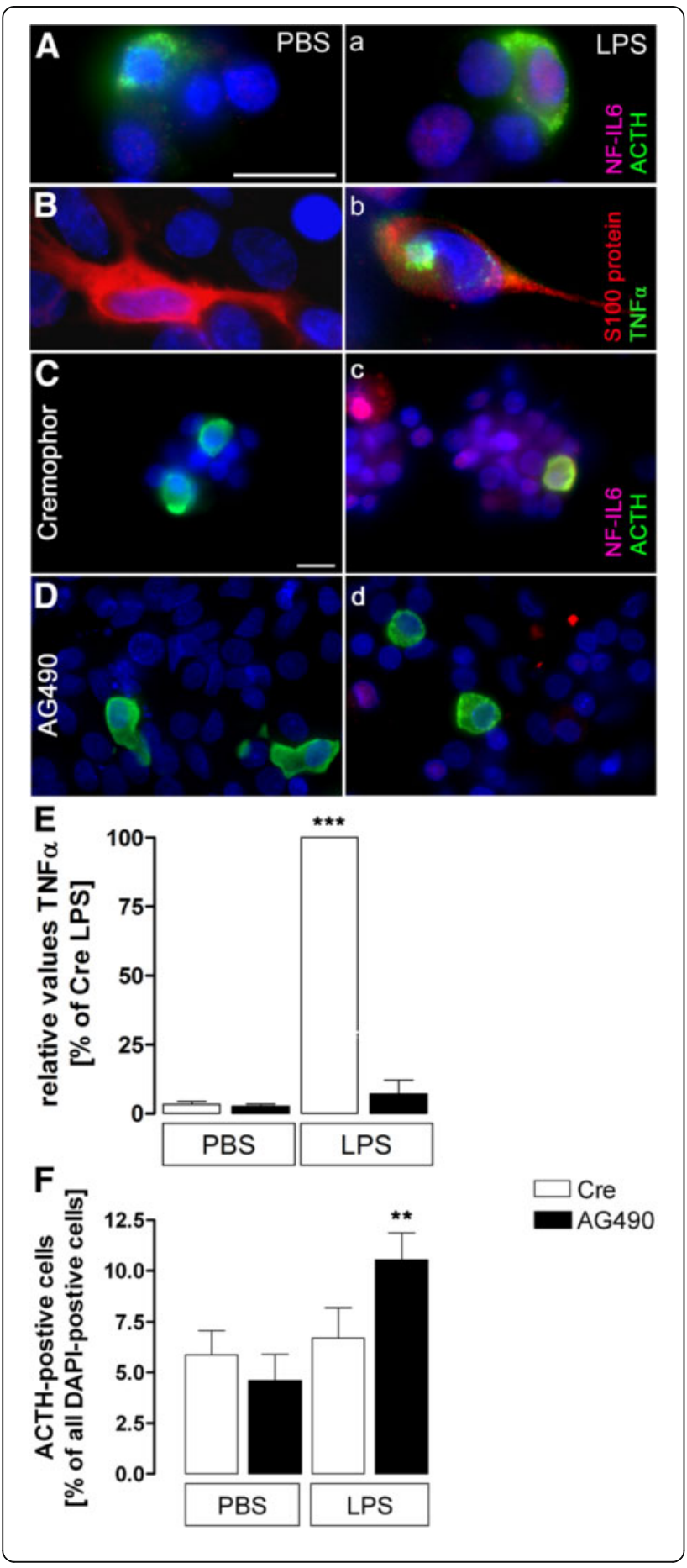

Figure 7 LPS-induced nuclear NF-IL6-IR is linked to ACTH and increased TNFa in the rat pituitary. $(A$, a) Representative microphotographs show that nuclear (DAPI, blue) NF-IL6-IR (red) co-localized with some ACTH-positive cells (green) $6 \mathrm{~h}$ after LPS $(100 \mu \mathrm{g} / \mathrm{mL}$, (a) but not PBS treatment (A) in primary cell cultures of the anterior pituitary lobe. (B, b) Moreover, LPS $(100 \mu \mathrm{g} / \mathrm{mL})$-induced TNFa-IR (green) in S100 protein-positive folliculostellate cells (red) $6 \mathrm{~h}$ after stimulation (b), compared to PBS controls (B). (C, c and D, d) In a different set of experiments, pretreatment $(30 \mathrm{~min}, 100 \mu \mathrm{M})$ with the JAK-STAT inhibitor AG490 reduced LPS (100 $\mathrm{\mu g} / \mathrm{mL})$-induced NF-IL6-IR partly in ACTH-IR cells (green) of the anterior pituitary lobe $6 \mathrm{~h}$ after stimulation (d), compared to solvent (cremophor, Cre) -treated controls (c). Brightness, contrast, and color balance were adjusted for better representation of the actual data. Scale bars in $\mathbf{A}$ (applies to $\mathbf{A}, \mathbf{a}, \mathbf{B}$ and b) and $\mathbf{C}$ (applies to C, c, D and $\mathbf{d}$ ) represent $10 \mu \mathrm{m}$. (E) Relative TNFa concentration in cell culture supernatants, in PBS- or LPS-stimulated and cremophor (Cre) or AG490 preincubated primary cell cultures are presented as percentage of LPS- and Cre-stimulated wells (100\%) as calculated for each experiment. Means of two to three wells of the means (of each independent experiment, $n=3$ ) were calculated and revealed a dramatic LPS- and Cre-induced TNFa-increase that was abolished by AG490 preincubation. (F) Counting of ACTH-IR cells as percentage of all cells in anterior pituitary cell cultures showed a significant increase of ACTH-positive cells after AG490 pretreatment in LPS-stimulated cultures (means of three independent experiments). AG490 did not show any significant effect on the amount of ACTH-positive cells in PBS-treated controls. ${ }^{*}$ LPS \& Cre vs. LPS \& AG490; ${ }^{* *} P<0.001$, ** $P<0.01$.

a fever-like process, some studies revealed a prostaglandin (PG)-dependent rise in $\mathrm{Tb}$ [52-54] and increased thermogenesis by brown adipose tissue [55]. However, these reports seem to pertain to anticipatory stress including the open field model (a similar but stronger stressor compared to the novel environment stress used in this study) but not others, which were reported to be independent of PG synthesis [56,57]. Our present results point to some limited contribution of motor activity to the concomitant increase of $\mathrm{Tb}$ in rats after exposure to a novel environment, which in this sense might rather represent hyperthermia than fever.

As mentioned before, NF-IL6-IR cell types differed between the two stress stimuli. We and others have previously shown LPS-induced NF-IL6-IR in the rat or mouse brain in vivo [1] and in vitro [18]. For instance, brain structures with a leaky blood-brain barrier (BBB) collectively called circumventricular organs (CVOs), such as the SFO, showed NF-IL6-IR in endothelial cells, astrocytes, activated microglia, perivascular macrophages, and neurons. Here, we again observed LPS-stimulated, NF-IL6 activation in perivascular macrophages and endothelial cells, suggesting that circulating mediators such as LPS and cytokines including IL-6 and TNF $\alpha$ might contribute to their stimulation in the pituitary. Since the posterior pituitary belongs to the CVOs and the anterior pituitary is devoid of a $\mathrm{BBB}$, such a direct action is probable and supports the longstanding 
hypothesis concerning immune-to-brain communication pathways via the humoral pathway [58]. The crucial role of perivascular macrophages [59-61] and endothelial cells $[5,62,63]$ in this response, both of which were activated during systemic inflammation, also suggests a direct influence of circulating inflammatory mediators on the pituitary and its activity. However, psychological stress did not induce NF-IL6-IR in endothelial cells and no significant increase was observed in the $\mathrm{SFO}$, a brain structure prone to detect circulating mediators. In addition, we did not observe a significant increase in circulating IL-6 levels in these animals, although previous results by others did [64]. In our experiments, this indicates that these IL-6-levels do not reach a threshold that would elicit a genomic activation in the brain as previously suggested for STAT3 activation by LPS-induced circulating IL-6 [65]. Moreover, the increase in $\mathrm{Tb}$ to an open field exposure was not altered in IL-6 deficient mice [66] confirming that NF-IL6 activation in specific cellular phenotypes and by distinct stress stimuli is dependent on different signaling pathways, for example, a humoral and a neuronal one.

In the posterior pituitary lobe we found NF-IL6-IR pituicytes and cells with strong nNOS-IR with high amounts of NF-IL6-IR cells lining the intermediate lobe (IL) after LPS stimulation. Such a strong nNOS-staining in the posterior lobe and lining the IL has been demonstrated before and was linked to indirect regulation of $\beta$-endorphin, a POMC-derived peptide, from the intermediate lobe [36]. Thus, NF-IL6 may play a role in this response; it also has been implicated in production of $\mathrm{NO}$ [67], which is known to modulate HPA-axis activity [68].

Another interesting cellular phenotype in the anterior pituitary lobe are S100-protein-positive folliculostellate cells, which also were NF-IL6-IR following LPS administration. These cells have been previously shown to produce IL-6 after LPS stimulation [43] involving the NFKB pathway [69]. Gloddek and colleagues (2001) reported that LPSinduced secretion of ACTH is mediated by IL-6, acting in the pituitary in a paracrine manner [70]. Here, we revealed for the first time folliculostellate cells as one of the sources of TNF production in the pituitary. Although TNF $\alpha$ expression has been observed throughout the pituitary [71-73], the cellular phenotype of TNF-expressing cells has not been determined previously. The shape of TNF $\alpha$ staining resembled the one that had been shown earlier for microglia in other primary cell cultures in the so-called trans-golgi apparatus [39]. Moreover, the release of this particular cytokine was inhibited by the JAK-STAT inhibitor AG490, which was accompanied by reduced NF-IL6-IR. Thus, the JAK-STAT3 and NF-IL6 pathway seem to be involved in this response. The functional role, however, of TNF $\alpha$ in the pituitary for HPA-axis activity remains controversial. Both, inhibitory [74] and stimulatory effects [75] in the pituitary have been reported [43] with TNF-binding sites existing in different cellular phenotypes including folliculostellate cells themselves [76]. Again, this indicates a potential ambivalent role for NF-IL6, either stimulating or inhibiting HPA-axis activity and pituitary/brain function, possibly mediated via TNF $\alpha$. Here, we found an increased percentage of ACTH-positive cells after AG490 pretreatment in LPSstimulated cell cultures of the anterior pituitary lobe, while the LPS-induced increase of TNF $\alpha$ levels in supernatant was abolished. This observation indicates that TNF $\alpha$ might, indeed, rather be an inhibitory factor for ACTH expression in response to LPS stimulation.

Recently, NFKB, which is also activated by TNF $\alpha$, was reported to be crucial for the stress response after LPS and open field stress in vivo [30]. While LPS-induced $\mathrm{NF \kappa B}$ activity increased IL-6-expression in folliculostellate cells, it inhibited ACTH expression in corticotropes. Mehet et al. (2012) proposed that this striking difference in the NFKB response, depending on the implicated cell phenotypes, represents a regulatory machinery that enhances CRH-activated HPA-axis activity at early stages. When CRH reaches high levels, LPS-induced activation in corticotropes might serve as a limiting inhibitory pathway. Opposed to this report, in another study, TNF-induced NFkB activation seemed to directly contribute to POMC expression in vitro [45]. Collectively, POMC expression most likely depends on several transcription factors including NFKB, STAT3, and NF-IL6, since their activity and function depends on physical interaction with each other [40,77]. For instance, NF-IL6 may enhance NFkBassociated signaling [78] and STAT3 enhances NF-IL6 activation [79], knowing that all of them can somehow contribute to POMC expression as mentioned before. In this regard, leukemia inhibitory factor (LIF) was shown to be important for STAT3- and NF-IL6-dependent POMC expression $[47,80]$. Indeed, LIF contributes to LPS-induced ACTH levels in vivo [81]. In the present study, we found some co-localization of STAT3 with NF-IL6 and of NFKB with NF-IL6, suggesting that such interactions might play an important role in the complex function of HPA-axis activation, although a time-controlled subsequent activation of the three inflammatory transcription factors (first NFkB, then STAT3, followed by NF-IL6) also seems to take place. However, some inhibitory functions of NF-IL6 when interacting with STAT3/NFKB has also been described previously $[82,83]$.

\section{Conclusions}

Overall, these present results show, for the first time, an activation of the pivotal inflammatory transcription factor, NF-IL6 following a psychological stressor, and reveal new insights in LPS-induced NF-IL6 activation in the pituitary. 
NF-IL6 function seems to be, in part, linked to STAT3, $\mathrm{NF} \kappa \mathrm{B}$, and HPA-axis activation. Moreover, we reveal evidence for distinct pathways in the spatiotemporal NF-IL6 activation after either psychological or inflammatory stress (that is, humoral vs. non-humoral). While brain perivascular macrophages are activated in response to both stressors, endothelial cells, pituicytes, CD68 positive cells, and corticotropes show NF-IL6 activation only after LPS stimulation. The role of NF-IL6/STAT3 in LPS-induced inflammation seems to involve modulation of TNF $\alpha$ expression in folliculostellate cells of the pituitary as shown by inhibition of LPS-induced TNF $\alpha$ levels in cell culture supernatants by the JAK-STAT/NF-IL6 inhibitor AG490. In addition, this treatment, that is, TNF $\alpha$ inhibition, was associated with increased numbers of ACTH-positive cells. Subsequently, not only STAT3, but also NF-IL6 activity might potentially be linked to a modulation of stress-axis activity, but this remains to be confirmed in future studies. As inflammatory transcription factors are important brain cell activation markers and therapeutical targets for a variety of endogenous (glucocorticoids) and exogenous (that is, [9]) antiinflammatory/inhibitory strategies, these observations are of high interest for a broad context of research areas and questions involving inflammatory as well as psychological stress models and brain inflammation.

\section{Additional file}

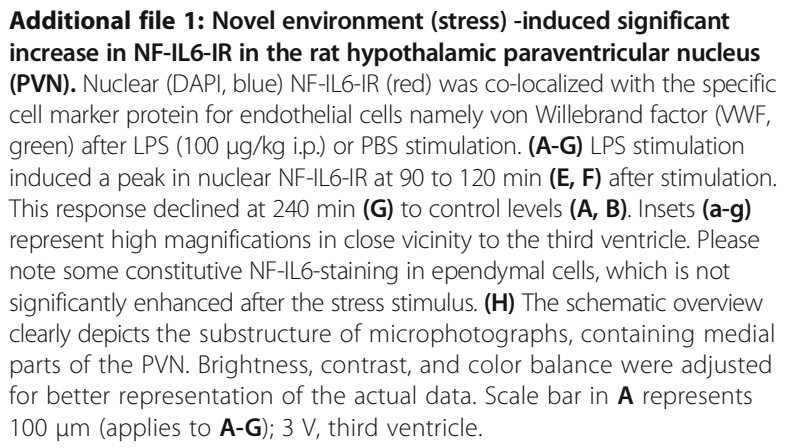

\footnotetext{
Abbreviations

ACTH: Adrenocorticotrope hormone; AL: Pituitary anterior lobe; BBB: Blood-brain barrier; CD: Cluster of differentiation; Crem: Cremophor; $\mathrm{CRH}$ : Corticotropin-releasing hormone; CVOs: Circumventricular organs; DMEM: Dulbecco's modified eagle medium; EBSS: Earle's balanced salt solution; GFAP: Glial fibrillary acidic protein; HBSS: Hanks balanced salt solution; HPA-axis: Hypothalamic-pituitary-adrenal-axis;

IHC: Immunohistochemistry; IR: Immunoreactivity; IL-6: Interleukin 6; IL: Pituitary intermediate lobe; LPS: Lipopolysaccharide; ME: Median eminence; NFkB: Nuclear factor kappa B; NF-IL6: Nuclear factor IL-6; NOS: Nitric oxide synthase; PVN: Hypothalamic paraventricular nucleus; PBS: Phosphate buffered saline; PG: Prostaglandin; PL: Pituitary posterior lobe;

POMC: Proopiomelanocortin; RT: Room temperature; STAT3: Signal transducer and activator of transcription 3; SFO: Subfornical organ; Tb: Core body temperature; TNFa: Tumor necrosis factor alpha; WWF: Von Willebrand factor.
}

\section{Competing interests}

The authors declare that they have no competing interests.

\section{Authors' contributions}

Conception and design of the experiments was done by RC, RJ, and GR $F F, R C, R J$, and DJ performed collection, analysis, and interpretation of data. $R C, R J, F F$, and DJ contributed to drafting the article or revising it critically for important intellectual content. All authors read and approved the final manuscript.

\section{Acknowledgments}

We would like to thank Ms. D. Marks, Ms. D. Ott, and Ms. J. Murgott for excellent technical assistance and A. Aguilar Valles for critically reading our manuscript. C. Rummel and this study were supported by the Emmy Noether Program of the German Research Foundation (DFG project RU 1397/2-1). Rabbit polyclonal anti-ACTH IgG was a gift from Dr. Blähser, Institute of Anatomy and Cytobiology, JLU Giessen, Germany.

Received: 25 July 2013 Accepted: 12 November 2013

Published: 26 November 2013

\section{References}

1. Damm J, Luheshi GN, Gerstberger R, Roth J, Rummel C: Spatiotemporal nuclear factor interleukin- 6 expression in the rat brain during lipopolysaccharide-induced fever is linked to sustained hypothalamic inflammatory target gene induction. J Comp Neuro/ 2011, 519:480-505.

2. Damm J, Wiegand F, Harden LM, Gerstberger R, Rummel C, Roth J: Fever, sickness behavior, and expression of inflammatory genes in the hypothalamus after systemic and localized subcutaneous stimulation of rats with the toll-like receptor 7 agonist imiquimod. Neuroscience 2012, 201:166-183.

3. Knorr C, Marks D, Gerstberger R, Muhlradt PF, Roth J, Rummel C: Peripheral and central cyclooxygenase (COX) products may contribute to the manifestation of brain-controlled sickness responses during localized inflammation induced by macrophage-activating lipopeptide-2 (MALP-2). Neurosci Lett 2010, 479:107-111.

4. Voss T, Barth SW, Rummel C, Gerstberger R, Hubschle T, Roth J: STAT3 and COX-2 activation in the guinea-pig brain during fever induced by the toll-like receptor-3 agonist polyinosinic:polycytidylic acid. Cell Tissue Res 2007, 328:549-561.

5. Rummel C, Inoue W, Sachot C, Poole S, Hubschle T, Luheshi GN: Selective contribution of interleukin- 6 and leptin to brain inflammatory signals induced by systemic LPS injection in mice. J Comp Neurol 2008, 511:373-395.

6. Gautron L, Lafon P, Chaigniau M, Tramu G, Laye S: Spatiotemporal analysis of signal transducer and activator of transcription 3 activation in rat brain astrocytes and pituitary following peripheral immune challenge. Neuroscience 2002, 112:717-729.

7. Nadjar A, Combe C, Layé S, Tridon V, Dantzer R, Amedee T, Parnet P: Nuclear factor $\mathrm{KB}$ nuclear translocation as a crucial marker of brain response to interleukin-1. A study in rat and interleukin-1 type I deficient mouse. J Neurochem 2003, 87:1024-1036.

8. Damm J, Harden L, Gerstberger R, Roth J, Rummel C: The putative JAK-STAT inhibitor AG490 exacerbates LPS-fever, reduces sickness behavior, and alters the expression of pro- and anti-inflammatory genes in the rat brain. Neuropharmacology 2013, 71:98-111.

9. Rummel C, Gerstberger R, Roth J, Hubschle T: Parthenolide attenuates LPS-induced fever, circulating cytokines and markers of brain inflammation in rats. Cytokine 2011, 56:739-748.

10. Kozak W, Wrotek S, Kozak A: Pyrogenicity of CpG-DNA in mice: role of interleukin-6, cyclooxygenases, and nuclear factor-kappaB. Am J Physiol Regul Integr Comp Physiol 2006, 290:R871-R880.

11. Lee JJ, Huang WT, Shao DZ, Liao JF, Lin MT: Blocking NF-kappaB activation may be an effective strategy in the fever therapy. Jpn J Physiol 2003, 53:367-375.

12. Rummel C, Barth SW, Voss T, Korte S, Gerstberger R, Hubschle T, Roth J: Localized vs. systemic inflammation in guinea pigs: a role for prostaglandins at distinct points of the fever induction pathways? Am J Physiol Regul Integr Comp Physiol 2005, 289:R340-R347.

13. Voss T, Rummel C, Gerstberger R, Hubschle T, Roth J: Fever and circulating cytokines induced by double-stranded RNA in guinea pigs: dependence 
on the route of administration and effects of repeated injections. Acta Physiol (Oxf) 2006, 187:379-389.

14. Welsch J, Hubschle T, Murgott J, Kirschning C, Rummel C, Gerstberger R, Roth J: Fever induction by systemic stimulation with macrophageactivating lipopeptide-2 depends upon TLR2 but not CD36. Innate Immun 2012, 18:541-559.

15. Laflamme N, Rivest S: Effects of systemic immunogenic insults and circulating proinflammatory cytokines on the transcription of the inhibitory factor kappaB alpha within specific cellular populations of the rat brain. J Neurochem 1999, 73:309-321.

16. Nakamura $\mathrm{K}$ : Central circuitries for body temperature regulation and fever. Am J Physiol Regul Integr Comp Physiol 2011, 301:R1207-R1228.

17. Lazarus M, Yoshida K, Coppari R, Bass CE, Mochizuki T, Lowell BB, Saper CB: EP3 prostaglandin receptors in the median preoptic nucleus are critical for fever responses. Nat Neurosci 2007, 10:1131-1133.

18. Ejarque-Ortiz A, Medina MG, Tusell JM, Perez-Gonzalez AP, Serratosa J, Saura J: Upregulation of CCAAT/enhancer binding protein beta in activated astrocytes and microglia. Glia 2007, 55:178-188.

19. Perez-Capote K, Saura J, Serratosa J, Sola C: Expression of C/EBPalpha and $\mathrm{C} /$ EBPbeta in glial cells in vitro after inducing glial activation by different stimuli. Neurosci Lett 2006, 410:25-30.

20. Lopez De Heredia L, Gengatharan A, Foster J, Mather S, Magoulas C: Bioluminescence imaging of the brain response to acute inflammation in living C/EBP reporter mice. Neurosci Lett 2011, 497:134-138.

21. Fields J, Gardner-Mercer J, Borgmann K, Clark I, Ghorpade A: CCAAT/enhancer binding protein beta expression is increased in the brain during HIV-1-infection and contributes to regulation of astrocyte tissue inhibitor of metalloproteinase-1. J Neurochem 2011, 118:93-104.

22. Qiu J, Yao S, Hindmarch C, Antunes V, Paton J, Murphy D: Transcription factor expression in the hypothalamo-neurohypophyseal system of the dehydrated rat: upregulation of gonadotrophin inducible transcription factor 1 mRNA is mediated by CAMP-dependent protein kinase A. J Neurosci 2007, 27:2196-2203.

23. Cortes-Canteli M, Luna-Medina R, Sanz-Sancristobal M, Alvarez-Barrientos A Santos A, Perez-Castillo A: CCAAT/enhancer binding protein beta deficiency provides cerebral protection following excitotoxic injury. J Cell Sci 2008, 121:1224-1234.

24. Sun W, Choi SH, Park SK, Kim SJ, Noh MR, Kim EH, Kim HJ, Kim H: Identification and characterization of novel activity-dependent transcription factors in rat cortical neurons. J Neurochem 2007, 100:269-278.

25. Nadeau S, Hein P, Fernandes KJ, Peterson AC, Miller FD: A transcriptional role for C/EBP beta in the neuronal response to axonal injury. Mol Cell Neurosci 2005, 29:525-535.

26. Cardinaux JR, Magistretti PJ: Vasoactive intestinal peptide, pituitary adenylate cyclase-activating peptide, and noradrenaline induce the transcription factors CCAAT/enhancer binding protein (C/EBP)-beta and C/EBP delta in mouse cortical astrocytes: involvement in CAMP-regulated glycogen metabolism. J Neurosci 1996, 16:919-929.

27. Kapadia R, Tureyen K, Bowen KK, Kalluri H, Johnson PF, Vemuganti R: Decreased brain damage and curtailed inflammation in transcription factor CCAAT/enhancer binding protein beta knockout mice following transient focal cerebral ischemia. J Neurochem 2006, 98:1718-1731.

28. Straccia M, Gresa-Arribas N, Dentesano G, Ejarque-Ortiz A, Tusell JM, Serratosa J, Sola C, Saura J: Pro-inflammatory gene expression and neurotoxic effects of activated microglia are attenuated by absence of CCAAT/enhancer binding protein beta. J Neuroinflammation 2011, 8:156.

29. Taubenfeld SM, Milekic MH, Monti B, Alberini CM: The consolidation of new but not reactivated memory requires hippocampal C/EBPbeta. Nat Neurosci 2001, 4:813-818

30. Mehet DK, Philip J, Solito E, Buckingham JC, John CD: Evidence from in vitro and in vivo studies showing that nuclear factor-kappaB within the pituitary folliculostellate cells and corticotrophs regulates adrenocorticotrophic hormone secretion in experimental endotoxaemia. J Neuroendocrinol 2012, 24:862-873.

31. Girotti M, Donegan JJ, Morilak DA: Influence of hypothalamic IL-6/gp130 receptor signaling on the HPA axis response to chronic stress. Psychoneuroendocrinology 2013, 38:1158-1169.

32. Roth J: Immunological and neuroendocrine modulation of fever in stress. Prog Brain Res 1998, 115:177-192.

33. Paxinos G, Watson C: The Rat Brain in Stereotaxic Coordinates. 4th edition. San Diego, CA: Academic; 1998.
34. Blähser S: The ACTH-immunoreactive system in the brain of the white-crowned sparrow, Zonotrichia leucophrys gambelii (Passeriformes, Emberizidae). Histochemistry 1988, 88:309-312.

35. Ott D, Murgott J, Rafalzik S, Wuchert F, Schmalenbeck B, Roth J, Gerstberger R Neurons and glial cells of the rat organum vasculosum laminae terminalis directly respond to lipopolysaccharide and pyrogenic cytokines. Brain Res 2010, 1363:93-106.

36. Crack PJ, Autelitano DJ, Smith Al: The involvement of nitric oxide in the secretion of beta-endorphin from the pituitary intermediate lobe of the rat. Brain Res 1997, 761:113-120.

37. Carretero J, Weruaga E, Hernandez E, Burks D, Riesco JM, Rubio M, Brinon JG, Aijon J, Vazquez R, Alonso JR: Dopaminergic modulation of nNOS expression in the pituitary gland of male rat. Anat Embryol (Berl) 2003, 207:381-388.

38. Lee $Y$, Kim JM, Lee EJ: Functional expression of CXCR4 in somatotrophs: CXCL12 activates GH gene, GH production and secretion, and cellular proliferation. J Endocrinol 2008, 199:191-199.

39. Wuchert F, Ott D, Murgott J, Rafalzik S, Hitzel N, Roth J, Gerstberger R: Rat area postrema microglial cells act as sensors for the toll-like receptor-4 agonist lipopolysaccharide. J Neuroimmunol 2008, 204:66-74

40. Agrawal A, Cha-Molstad H, Samols D, Kushner I: Overexpressed nuclear factor-kappaB can participate in endogenous C-reactive protein induction, and enhances the effects of C/EBPbeta and signal transducer and activator of transcription-3. Immunology 2003, 108:539-547.

41. Gautron L, Lafon P, Tramu G, Laye S: In vivo activation of the interleukin-6 receptor/gp130 signaling pathway in pituitary corticotropes of lipopolysaccharide-treated rats. Neuroendocrinology 2003, 77:32-43.

42. Parnet $P$, Pousset $F$, Laye S: NF kappa B activation in mouse pituitary: comparison of response to interleukin-1 beta and lipopolysaccharide. J Neuroendocrinol 2003, 15:304-314

43. Turnbull AV, Rivier CL: Regulation of the hypothalamic-pituitary-adrenal axis by cytokines: actions and mechanisms of action. Physiol Rev 1999, 79:1-71.

44. Chrousos GP: The hypothalamic-pituitary-adrenal axis and immune-mediated inflammation. N Engl J Med 1995, 332:1351-1362.

45. Takayasu S, Iwasaki Y, Nigawara T, Asai M, Yoshida M, Kageyama K, Suda T: Involvement of nuclear factor-kB and Nurr-1 in cytokine-induced transcription of proopiomelanocortin gene in AtT20 corticotroph cells. Neuroimmunomodulation 2010, 17:88-96.

46. Arzt E: gp130 cytokine signaling in the pituitary gland: a paradigm for cytokine-neuro-endocrine pathways. J Clin Invest 2001, 108:1729-1733.

47. Abbud RA, Kelleher R, Melmed S: Cell-specific pituitary gene expression profiles after treatment with leukemia inhibitory factor reveal novel modulators for proopiomelanocortin expression. Endocrinology 2004, 145:867-880.

48. Stephanou A, Okosi A, Knight RA, Chowdrey HS, Latchman DS: C/EBP activates the human corticotropin-releasing hormone gene promoter. Mol Cell Endocrinol 1997, 134:41-50.

49. Givalois L, Dornand J, Mekaouche M, Solier MD, Bristow AF, Ixart G, Siaud P, Assenmacher I, Barbanel G: Temporal cascade of plasma level surges in $\mathrm{ACTH}$, corticosterone, and cytokines in endotoxin-challenged rats. Am J Physiol 1994, 267:R164-R170.

50. Samuelsson AM, Ohrn I, Dahlgren J, Eriksson E, Angelin B, Folkow B, Holmang A: Prenatal exposure to interleukin- 6 results in hypertension and increased hypothalamic-pituitary-adrenal axis activity in adult rats. Endocrinology 2004, 145:4897-4911.

51. Romanovsky AA: Thermoregulation: some concepts have changed. Functional architecture of the thermoregulatory system. Am J Physiol Regul Integr Comp Physiol 2007, 292:R37-R46.

52. Singer R, Harker CT, Vander AJ, Kluger MJ: Hyperthermia induced by open-field stress is blocked by salicylate. Physiol Behav 1986, 36:1179-1182

53. Kluger MJ, O'Reilly B, Shope TR, Vander AJ: Further evidence that stress hyperthermia is a fever. Physiol Behav 1987, 39:763-766.

54. Morimoto A, Watanabe T, Morimoto K, Nakamori T, Murakami N: Possible involvement of prostaglandins in psychological stress-induced responses in rats. J Physiol 1991, 443:421-429.

55. Lkhagvasuren B, Nakamura $Y$, Oka T, Sudo N, Nakamura K: Social defeat stress induces hyperthermia through activation of thermoregulatory sympathetic premotor neurons in the medullary raphe region. Eur $J$ Neurosci 2011, 34:1442-1452.

56. Oka T, Oka K, Hori T: Mechanisms and mediators of psychological stress-induced rise in core temperature. Psychosom Med 2001, 63:476-486. 
57. Bouwknecht JA, Olivier B, Paylor RE: The stress-induced hyperthermia paradigm as a physiological animal model for anxiety: a review of pharmacological and genetic studies in the mouse. Neurosci Biobehav Rev 2007, 31:41-59.

58. Roth J, Harré EM, Rummel C, Gerstberger R, Hübschle T: Signaling the brain in systemic inflammation: role of sensory circumventricular organs. Front Biosci 2004, 9:290-300.

59. Serrats J, Schiltz JC, Garcia-Bueno B, van Rooijen N, Reyes TM, Sawchenko PE: Dual roles for perivascular macrophages in immune-to-brain signaling. Neuron 2010, 65:94-106.

60. Schiltz JC, Sawchenko PE: Signaling the brain in systemic inflammation: the role of perivascular cells. Front Biosci 2003, 8:s1321-s1329.

61. Derijk R, Van Rooijen N, Tilders FJ, Besedovsky HO, Del Rey A, Berkenbosch F: Selective depletion of macrophages prevents pituitary-adrenal activation in response to subpyrogenic, but not to pyrogenic, doses of bacterial endotoxin in rats. Endocrinology 1991, 129:330-338.

62. Matsumura K, Kobayashi S: Signaling the brain in inflammation: the role of endothelial cells. Front Biosci 2004, 9:2819-2826.

63. Rummel C, Voss T, Matsumura K, Korte S, Gerstberger R, Roth J, Hübschle T: Nuclear STAT3 translocation in guinea pig and rat brain endothelium during systemic challenge with lipopolysaccharide and interleukin-6. J Comp Neurol 2005, 491:1-14.

64. LeMay LG, Vander AJ, Kluger MJ: The effects of psychological stress on plasma interleukin-6 activity in rats. Physiol Behav 1990, 47:957-961.

65. Rummel C, Hübschle T, Gerstberger R, Roth J: Nuclear translocation of the transcription factor STAT3 in the guinea pig brain during systemic or localised inflammation. J Physiol 2004, 557:671-687.

66. Butterweck $V$, Prinz S, Schwaninger M: The role of interleukin-6 in stress-induced hyperthermia and emotional behaviour in mice. Behav Brain Res 2003, 144:49-56.

67. Kolyada AY, Madias NE: Transcriptional regulation of the human iNOS gene by IL-1beta in endothelial cells. Mol Med 2001, 7:329-343.

68. Lopez-Figueroa MO, Day HE, Akil H, Watson SJ: Nitric oxide in the stress axis. Histol Histopathol 1998, 13:1243-1252.

69. Lohrer P, Gloddek J, Nagashima AC, Korali Z, Hopfner U, Pereda MP, Arzt E, Stalla GK, Renner U: Lipopolysaccharide directly stimulates the intrapituitary interleukin- 6 production by folliculostellate cells via specific receptors and the p38alpha mitogen-activated protein kinase/nuclear factor-kappaB pathway. Endocrinology 2000, 141:4457-4465.

70. Gloddek J, Lohrer P, Stalla J, Arzt E, Stalla GK, Renner U: The intrapituitary stimulatory effect of lipopolysaccharide on ACTH secretion is mediated by paracrine-acting IL-6. Exp Clin Endocrinol Diabetes 2001, 109:410-415.

71. Gatti S, Bartfai T: Induction of tumor necrosis factor-alpha mRNA in the brain after peripheral endotoxin treatment: comparison with interleukin-1 family and interleukin-6. Brain Res 1993, 624:291-294.

72. Layé S, Parnet $P$, Goujon E, Dantzer R: Peripheral administration of lipopolysaccharide induces the expression of cytokine transcripts in the brain and pituitary of mice. Brain Res Mol Brain Res 1994, 27:157-162.

73. Pitossi F, del Rey A, Kabiersch A, Besedovsky H: Induction of cytokine transcripts in the central nervous system and pituitary following peripheral administration of endotoxin to mice. J Neurosci Res 1997, 48:287-298

74. Gaillard RC, Turnill D, Sappino P, Muller AF: Tumor necrosis factor alpha inhibits the hormonal response of the pituitary gland to hypothalamic releasing factors. Endocrinology 1990, 127:101-106.

75. Milenkovic L, Rettori V, Snyder GD, Beutler B, McCann SM: Cachectin alters anterior pituitary hormone release by a direct action in vitro. Proc Natl Acad Sci USA 1989, 86:2418-2422

76. Kobayashi H, Fukata J, Murakami N, Usui T, Ebisui O, Muro S, Hanaoka I, Inoue K, Imura H, Nakao K: Tumor necrosis factor receptors in the pituitary cells. Brain Res 1997, 758:45-50.

77. Yoshida Y, Kumar A, Koyama Y, Peng H, Arman A, Boch JA, Auron PE: Interleukin 1 activates STAT3/nuclear factor-kappaB cross-talk via a unique TRAF6- and p65-dependent mechanism. J Biol Chem 2004, 279:1768-1776.

78. Cappello C, Zwergal A, Kanclerski S, Haas SC, Kandemir JD, Huber R, Page S, Brand K: C/EBPbeta enhances NF-kappaB-associated signalling by reducing the level of IkappaB-alpha. Cell Signal 2009, 21:1918-1924.

79. Niehof M, Streetz K, Rakemann T, Bischoff SC, Manns MP, Horn F, Trautwein C: Interleukin-6-induced tethering of STAT3 to the LAP/C/EBPbeta promoter suggests a new mechanism of transcriptional regulation by STAT3. J Biol Chem 2001, 276:9016-9027.

80. Bousquet C, Zatelli MC, Melmed S: Direct regulation of pituitary proopiomelanocortin by STAT3 provides a novel mechanism for immuno-neuroendocrine interfacing. J Clin Invest 2000, 106:1417-1425.

81. Watanobe H, Suda T: A significant role of leukemia inhibitory factor in the brain and periphery in endotoxin stimulation of adrenocorticotropin secretion in the rat. Brain Res 2000, 865:97-101.

82. Zwergal A, Quirling M, Saugel B, Huth KC, Sydlik C, Poli V, Neumeier D, Ziegler-Heitbrock HW, Brand K: C/EBP beta blocks p65 phosphorylation and thereby NF-kappa B-mediated transcription in TNF-tolerant cells. $\mathrm{J}$ Immunol 2006, 177:665-672.

83. Nishinakamura H, Minoda Y, Saeki K, Koga K, Takaesu G, Onodera M, Yoshimura A, Kobayashi T: An RNA-binding protein alphaCP-1 is involved in the STAT3-mediated suppression of NF-kappaB transcriptional activity. Int Immunol 2007, 19:609-619.

doi:10.1186/1742-2094-10-140

Cite this article as: Fuchs et al: Activation of the inflammatory transcription factor nuclear factor interleukin-6 during inflammatory and psychological stress in the brain. Journal of Neuroinflammation 2013 10:140.

\section{Submit your next manuscript to BioMed Central and take full advantage of:}

- Convenient online submission

- Thorough peer review

- No space constraints or color figure charges

- Immediate publication on acceptance

- Inclusion in PubMed, CAS, Scopus and Google Scholar

- Research which is freely available for redistribution 